\title{
Dissolution of delta phase in Ni-based superalloy during linear friction welding: integrated multiphysics computational process modelling
}

\author{
Saviour I. Okeke ${ }^{1,2,3} \cdot$ Noel M. Harrison ${ }^{1,2,3}$ (D) Mingming Tong ${ }^{1,2,3}$ \\ Received: 26 January 2021 / Accepted: 1 June 2021 / Published online: 15 June 2021 \\ (C) The Author(s) 2021
}

\begin{abstract}
Linear friction welding (LFW) is an increasingly popular solid-state joining method for challenging applications such as integrated blade disk of aero-engines. However, the influence of friction-generated heat on the material microstructural evolution, material deformation and resultant mechanical performance of the manufactured components is not well understood. A novel integrated multiphysics computational modelling is presented for predicting the component-scale microstructural evolution of IN718 alloy during LFW. A modified time-temperature equivalence formulation was implemented for predicting the evolution of the $\delta$ phase, which was coupled with thermomechanical modelling of the LFW process. There is reasonably good agreement between the computational modelling results of this paper and the experimental results from the literature in terms of $\delta$ phase volume fraction and weld temperature. The integrated multiphysics computational modelling predicts the influence of process parameters on thermomechanical and microstructural processes of IN718 LFW. By systematically analysing the influence of 10 different LFW process parameter configurations, the friction pressure was identified as the most influential process parameter determining the extent of $\delta$ phase dissolution and weld temperature during LFW.
\end{abstract}

Keywords Linear friction welding $\cdot$ Inconel $718 \cdot$ Delta phase $\cdot$ Microstructural modelling $\cdot$ Time-temperature equivalence Multiphysics modelling

Nomenclature
$\begin{array}{ll}\text { Acronyms and Greek } \\ \mathrm{Al} & \text { Aluminium } \\ \mathrm{BM} & \text { Base metal } \\ \mathrm{DRX} & \text { Dynamic recrystallization } \\ \mathrm{HV} & \text { Vickers Pyramid Number } \\ \mathrm{IN718} & \text { Inconel 718 } \\ \mathrm{LFW} & \text { Linear friction welding } \\ \mathrm{Nb} & \text { Niobium } \\ \mathrm{Ni} & \text { Nickel }\end{array}$

Noel M. Harrison

noel.harrison@nuigalway.ie

1 Mechanical Engineering, School of Engineering, College of Science and Engineering, NUI Galway, Galway, Ireland

2 I-Form, the SFI Research Centre for Advanced Manufacturing, Galway, Ireland

3 Ryan Institute for Environmental, Marine and Energy Research, NUI Galway, Galway, Ireland

$\begin{array}{ll}\text { Ti } & \text { Titanium } \\ \text { TTE } & \text { Time-temperature equivalence } \\ \text { VUSDFLD } & \text { Abaqus/Explicit user-defined field subroutine } \\ \delta & \text { Delta phase } \\ \varepsilon & \text { Plastic strain } \\ \varepsilon^{\prime} & \text { Strain rate }[1 / \mathrm{s}] \\ \gamma^{\prime \prime} & \text { Gamma prime phase } \\ \gamma^{\prime} & \text { Gamma double prime phase } \\ \mu & \text { Friction coefficient } \\ \sigma_{s} & \text { Shear flow stress }[\mathrm{MPa}] \\ \sigma_{y} & \text { Yield flow stress [MPa] } \\ \tau_{f r} & \text { Frictional shear stress }[\mathrm{MPa}]\end{array}$

Abbreviations

$A_{0} \quad \mathrm{~mm}$, Oscillating amplitude

$A(\varepsilon), \quad n(\varepsilon)$, IN718 material constants

$\alpha(\varepsilon)$

$D_{0} \quad \mu \mathrm{m}^{2} \mathrm{~s}^{-1}$, Diffusion coefficient

$f_{0} \quad \mathrm{~Hz}$, Oscillating frequency

$l \quad \mu \mathrm{m}$, Radius of $\gamma$ matrix

$L_{a} \quad \mathrm{~mm}$, Axial shortening 


$\begin{array}{ll}Q & \begin{array}{l}\mathrm{J} \cdot \mathrm{mol}^{-1}, \text { Activation energy for dissolution of } \delta \\ \text { phase }\end{array} \\ Q(\varepsilon) & \mathrm{J} \cdot \mathrm{mol}^{-1}, \text { Deformation activation energy } \\ Q_{S P I} & \mathrm{Wm}^{-2}, \text { Specific heat input } \\ p_{f} & \mathrm{MPa}, \text { Friction pressure } \\ r & \mu \mathrm{m}, \text { Radius of } \delta \text { phase } \\ R & \mathrm{~J} \cdot \mathrm{mol}^{-1} \mathrm{~K}^{-1}, \text { Gas constant } \\ t & \text { s, Time } \\ T_{\text {solid }} & { }^{\circ} \mathrm{C}, \text { Solidus temperature } \\ T_{\text {liq }} & { }^{\circ} \mathrm{C}, \text { Liquidus temperature } \\ X & \text { at. } \%, \text { Atomic fraction (atomic per cent) }\end{array}$

\section{Introduction}

Linear friction welding (LFW) is an energy-efficient, highly automated solid-state joining method that can produce highquality welds by rapidly oscillating one workpiece relative to another under large compressive force. During LFW, friction heat is generated at the interface of two workpieces, which are in contact and in rapid relative motion [1,2]. As the temperature of the material at the friction interface increases, it softens and is extruded as a flash in the direction of oscillation due to the continued compressive forces. Thus, flash formation is accompanied by an overall shortening of workpiece in the axis of applied force. LFW can avoid hot cracking that is often found in fusion welding [1,2]. It is a self-cleaning process and does not use filler metal [1]. LFW can join similar and dissimilar alloys in varying geometric configurations [1-4]. It has been applied extensively for joining highperformance materials (e.g. nickel-based superalloys) with application in extreme environments (e.g. integrated blade disk of aero-engines). Despite the known benefits and applications of LFW, the influence of friction heat and friction force on the material microstructural evolution, material deformation and resultant mechanical performance of the manufactured components are still not well understood.

Nickel (Ni)-based superalloys are complex alloys that retain high strength, creep resistance and corrosion resistance at temperatures up to $1200{ }^{\circ} \mathrm{C}$, which is about $90 \%$ of their melting points $[1,3,5]$. IN718 is a precipitationstrengthened Ni-based superalloy that has been widely used in varied LFW applications, including aero-engines, steam turbine power plants and nuclear power systems $[3,5,6]$. In IN718, $\gamma^{\prime \prime}\left(\mathrm{Ni}_{3} \mathrm{Nb}\right)$ and $\gamma^{\prime}\left(\mathrm{Ni}_{3} \mathrm{Al}\right)$ are the primary and secondary strengthening precipitates, respectively. The $\delta$ phase has the same composition as $\gamma^{\prime \prime}$ phase, precipitates at the grain boundaries and prevents grain boundary migration [7-9]. The microstructure of an alloy determines its material properties, as demonstrated via local hardness profiles around an IN718 LFW weld joint corresponding to local $\gamma$ grain size and $\gamma^{\prime}$ volume fraction, size and distribution [10-13]. Ma et al. found that the tensile strength and hardness of several IN718 weld joints were lower than the tensile strength and hardness of parent (non-welded) metal [13]. They identified rapid weld temperature variation and resultant conversion of $\gamma^{\prime}$ and $\gamma^{\prime \prime}$ phases to $\delta$ phase as factors responsible for the decreased mechanical properties of the weld. It was found that after multiple long-term exposures to high-temperature cycles, IN718 welds degrade and become difficult to repair by welding because of the accumulation of $\mathrm{Nb}$-rich $\delta$ phase in grain boundaries and the depletion of $\delta$ phase in adjacent intergranular regions in the IN718 microstructure $[14,15]$. Mary and Jahazi found that the loss of the $\delta$ phase in IN718 weld joint facilitates dynamic recrystallisation and dynamic recovery of $\gamma$ grains in the weld joint during LFW [16].

The influence of thermomechanical process on the microstructural properties and mechanical behaviour of IN718 alloy has been reported in multiple studies. For instance, significant changes in the microstructure of $\gamma^{\prime}, \gamma^{\prime \prime}$ and $\delta$ phases can occur on the friction interface of IN718 weld during LFW, in terms of volume fraction, size and spatial distribution $[1,10,11]$. These microstructural and resultant mechanical properties change when the friction interface is exposed to high temperature, high heating rate, high plastic strain and rapid cooling during LFW $[1,10,11]$. Roder et al. and Preuss et al. observed a $600-\mu \mathrm{m}$ wide soft region on both sides of the friction interface of IN718 inertia friction welds where $\gamma^{\prime}, \gamma^{\prime \prime}$ and $\delta$ phases are fully dissolved $[17,18]$. This material softening, accompanied by dissolution of $\gamma^{\prime}, \gamma^{\prime \prime}$ and $\delta$ phases on the friction interface, is beneficial for flash formation and improving weld integrity $[17,18]$. Yang found that the rate of $\delta$ phase dissolution was affected by the heating rate while simulating microstructural evolution during thermomechanical processing of IN718 using Gleeble testing [10]. Other researchers agree with Yang that the heating rate as well as the size of $\gamma^{\prime}$ phase influence the rate of $\gamma^{\prime}$ phase dissolution in Astroloy and AD730 Ni-based superalloys [19-21]. In order to optimise the design of LFW process parameters, it is important to systematically and quantitatively analyse the influence of thermomechanical processes on the microstructural evolution of IN718, for example, the $\delta$ precipitate, during LFW process.

There are three key process parameters often considered for optimising the LFW process, which are friction pressure, oscillating frequency and oscillating amplitude. These key LFW process parameters have been experimentally varied at different levels, and their influence on temperature, heating rate and resultant microstructure and mechanical properties of IN718 weld have been reported [10-13, 22, 23]. Ma et al. found that the weld microstructure was significantly affected by high heat input resulting from increased friction pressure and amplitude [13]. They observed that dynamic recrystallization (DRX) and recovery were achieved by increasing the friction-generated heat. Similar results of enhanced DRX were reported by other researchers [24-26]. The temperature- 
dependent yield strength of IN718 material has been reported to decrease with increasing friction pressure, leading to an increase in overall plastic strain and rate of flash formation at the friction interface $[10,11,23]$. Geng et al. pointed out that the flow velocity of materials at the friction interface increased when they increased oscillating frequency and oscillating amplitude during LFW of IN718 [22]. In another study, Qin et al. showed that increasing friction pressure resulted in increased value of maximum friction interface temperature during LFW [23]. Also, increasing oscillating frequency and oscillating amplitude resulted in increased values of maximum temperature and strain rate at the friction interface during LFW. Studies have noted that the regions of the friction interface without $\delta$ phase coincide with the regions where the temperature exceeds the solvus temperature of $\delta$ phase during LFW $[1,10,11]$. The microstructural evolution of $\gamma^{\prime}$ and $\delta$ phases has often been characterised by physically simulating LFW process using thermomechanical simulator testing $[10,19,27,28]$. However, there are challenges in measuring the dissolution kinetics specifically in the supersolvus temperature range due to the rapidly varying volume fraction of precipitates [27].

While the temperature evolution of weld can be experimentally measured by using thermocouples, it can only be conducted at places of weld reasonably away from the friction interface [11, 24]. Moreover, the measurement of stress and strain and particularly their evolution during LFW process can be very challenging using experimental methods [1, 24]. Chamanfar et al. and Masoumi et al. reported that the local plastic deformation, strain and strain rate at the friction interface could not be directly measured by strain gauges due to the dynamic nature and overall configuration of $\operatorname{LFW}[1,24]$. Moreover, the dynamic evolution of material microstructure during LFW process is very difficult to characterise using experimental measurement. Computational modelling method is very good at predicting some dynamically evolving processes and phenomena, such as thermomechanical processes and material microstructural evolution during material processing. Extensive computational modelling research has been published on the thermomechanical processes of IN718 LFW [22, 23, 29-35]. However, there has been very little work published in relation to the computational modelling for the material microstructural evolution during IN718 LFW, especially relating to predicting the dissolution of $\delta$ phase during LFW.

The objective of this study is to develop an integrated multiphysics computational modelling for predicting the coupled thermomechanical-microstructural processes (at the component scale) during IN718 LFW. This modelling integrates the thermomechanical submodel with the microstructural submodel by using sequential coupling. It particularly predicts the dissolution process of $\delta$ phase during LFW.

\section{Methods}

A 2D computational modelling framework for LFW was developed within the general-purpose finite element solver ABAQUS and user-defined field subroutine (VUSDFLD) [36]. The integrated multiphysics computational modelling was developed by sequentially coupling a thermomechanical submodel for LFW process to a novel microstructural submodel for the $\delta$ phase dissolution of IN718 alloy. The $2 \mathrm{D}$ thermomechanical modelling reduces overall computation time and gives a reasonable representation of the LFW process.

\subsection{Thermomechanical model}

The thermomechanical model for LFW process was previously presented in a study by the authors [29]. In the thermomechanical modelling of this study, the two workpieces of the friction pair are both deformable. The elastoplastic deformation of workpieces, generation of friction heat at the friction interface and heat transfer of the workpieces are fully coupled in the thermomechanical model. The thermomechanical model was implemented by using the finite element Abaqus/Explicit solver, which is recommended for fully coupled thermal-mechanical problems and highly capable of resolving contact problems as well as overcoming excessive element distortion using dynamic remeshing [36].

\subsubsection{Setup of thermomechanical modelling}

In the computational modelling of this paper, the two workpieces - top and bottom - were discretized using the deformable plane strain formulation with elements defined in the

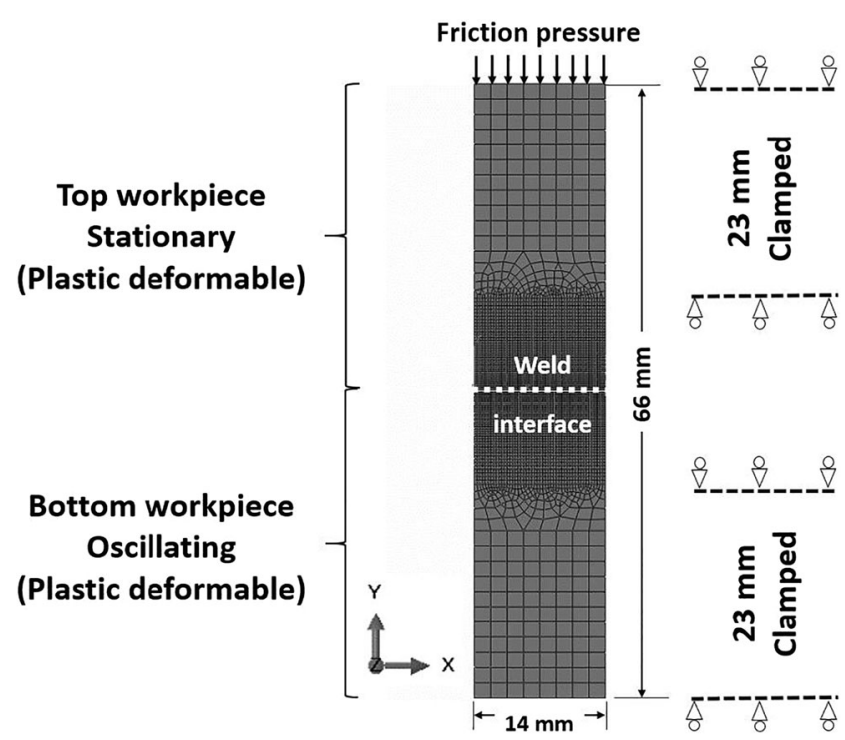

Fig. 1 Setup of the 2D thermomechanical model for LFW process with friction-paired deformable workpieces 
$\mathrm{X}$-Y plane and restricting deformation only to the defined plane. The two deformable workpieces shown in Fig. 1 have the same dimension of $33 \mathrm{~mm}$ by $14 \mathrm{~mm}$. They are adjacent to each other, and there is an initial contact at the intended friction interface of workpieces. The workpiece dimensions employed in the computational modelling of this paper are same dimensions as the IN718 LFW experiments of Geng et al. and Qin et al. [11,23]. Their study provided the experimental data utilised in this paper for model verification.

Element types of CPE4RT and CPE3T (4-node and 3-node thermally coupled, displacement and temperature, reduced integration, hourglass control) were specified on both workpieces. The thermomechanical modelling for the LFW process lasts for $5.0 \mathrm{~s}$ of welding time. Both workpieces use a similar mesh discretisation procedure involving two structured mesh zones and one unstructured mesh zone. There are 2454 elements and 2588 nodes for the entire model. Mesh refinement is specifically directed towards the friction interface and periphery of workpieces, where high temperature and high plastic strain are expected. Seeding was defined on the edges of the workpieces, only at the regions closest to the friction interface.

\subsubsection{Constitutive material model and friction model}

The elastic response of IN718 is assumed to be governed by Hooke's Law. Equations 1 and 2 denote the straincompensated Arrhenius equation for the plastic material behaviour of IN718 alloy during LFW [22, 23, 31].

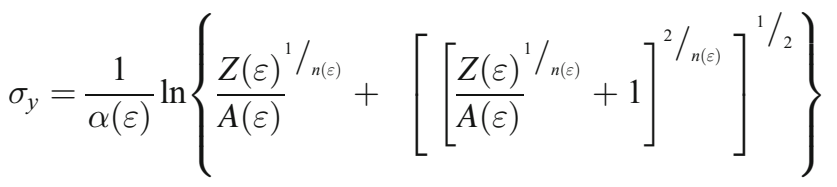

$Z(\varepsilon)=\dot{\varepsilon} \exp \left[\frac{Q(\varepsilon)}{R T}\right]$

where $\sigma_{y}$ is the yield flow stress, $\dot{\varepsilon}$ is the strain rate, $T$ is the absolute temperature and $R$ is the universal gas constant. $Q(\varepsilon)$ is the deformation activation energy; $\alpha(\varepsilon), n(\varepsilon)$ and $A(\varepsilon)$ are material constants. They are respectively expressed as polynomial functions of deformation strain as:

$$
\begin{gathered}
A(\varepsilon)=B_{0}+B_{1} \varepsilon+B_{2} \varepsilon^{2}+B_{3} \varepsilon^{3}+B_{4} \varepsilon^{4}+B_{5} \varepsilon^{5} \\
n(\varepsilon)=C_{0}+C_{1} \varepsilon+C_{2} \varepsilon^{2}+C_{3} \varepsilon^{3}+C_{4} \varepsilon^{4}+C_{5} \varepsilon^{5} \\
Q(\varepsilon)=D_{0}+D_{1} \varepsilon+D_{2} \varepsilon^{2}+D_{3} \varepsilon^{3}+D_{4} \varepsilon^{4}+D_{5} \varepsilon^{5} \\
\ln A(\varepsilon)=F_{0}+F_{1} \varepsilon+F_{2} \varepsilon^{2}+F_{3} \varepsilon^{3}+F_{4} \varepsilon^{4}+F_{5} \varepsilon^{5}
\end{gathered}
$$

The coefficients of polynomial functions for the alloy material can be found in the research [30].

In this study, friction behaviour was represented by a plastically deformable friction pair. Contact between two workpieces was formulated by using the 'surface-to-surface explicit' contact algorithm. The magnitude of contact pressure was computed in the thermomechanical modelling during LFW. Normal contact interaction was defined as hard (explicit default). Penalty tangential workpiece interaction, which related to the transmission of shear stresses across the contact interface, was defined via the friction coefficient $[22,37]$. The friction coefficient depends on sliding velocity, friction interface temperature and contact pressure. This dependence can be expressed as:

$\mu=f\left(p_{f}, v_{s}, T\right)$

where $p_{f}$ is the contact friction pressure, $v_{s}$ is the sliding velocity and $T$ is the interface temperature between the contacting friction surfaces. An exponential function has been previously employed for the target alloy IN718, in the form of a modified Coulomb friction law expressed as [31]:

$\mu=a p_{f}^{b} T^{c} \exp \left(d v_{s}\right)$

where the constants $a, b, c$ and $d$ are specified as $0.12,-0.233$, 0.471 and -0.739 , respectively [31]. Further, the maximum frictional shear stress $\tau_{f r}$ cannot be higher than the shear flow stress of IN718 material. Thus, once the maximum shear stress reaches a limit, the temperature and strain rate-dependent limited shear stress $\sigma_{s}$ is implemented. This has been expressed by $[23,31]$ :

$\tau_{f r}=\min \left(\mu p_{n}, \frac{\sigma_{s}}{\sqrt{3}}\right)$

\subsubsection{Initial and boundary conditions}

Mechanical boundary conditions were defined on the stationary (top) workpiece as surface uniformly applied pressure,

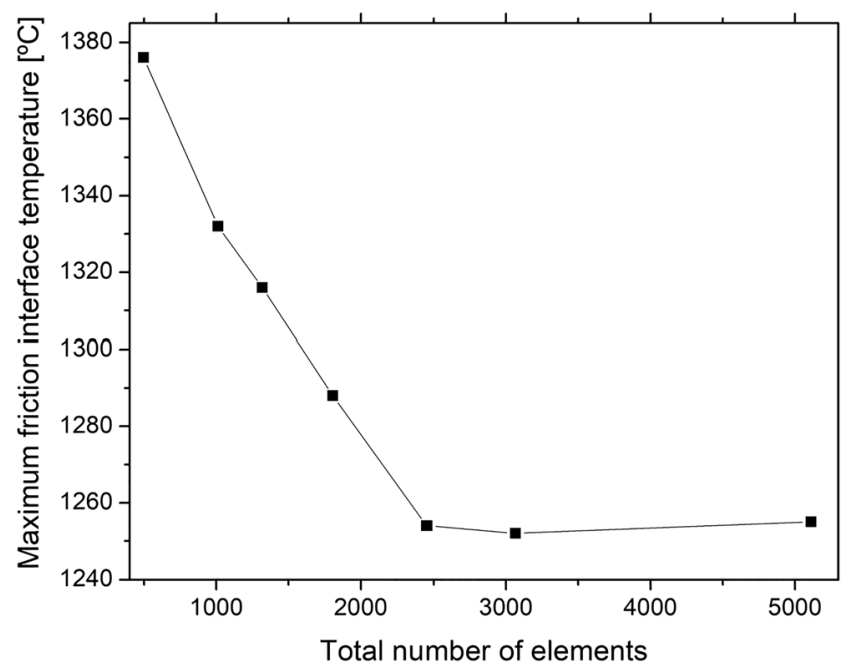

Fig. 2 Results of mesh dependency testing 
constrained $\mathrm{x}$-axis displacement and unconstrained $\mathrm{y}$-axis displacement (see Fig. 1). The oscillating (bottom) workpiece has $\mathrm{x}$-axis sinusoidal displacement, while displacement is constrained in the $\mathrm{y}$-axis. The $\mathrm{x}$-axis sinusoidal displacement of the oscillating workpiece is controlled by:

$x=A_{0} \sin 2 \pi f_{0} t$

where $A_{0}$ is the amplitude of oscillation $(\mathrm{mm}), f_{0}$ is the frequency of oscillation $(\mathrm{Hz})$ and $t$ is the instantaneous weld time, from 0.0 to $5.0 \mathrm{~s}$.

\subsubsection{Dynamic remeshing and mesh dependency analysis}

The arbitrary Lagrangian-Eulerian (ALE) adaptive meshing for automatic solution mapping was implemented to control excessive element distortion in the Abaqus/Explicit solver [36]. The mass-scaling algorithm was formulated at every analysis step in the Abaqus/Explicit solver. To ensure reasonable computational cost, a constant value of 800 was specified as the semi-automatic mass scaling objective definition at the beginning of each analysis step [36]. This semi-automatic mass scaling constant ensures that the kinematic energy is less than $5 \%$ of the internal energy [38]. A similar criterion for defining mass scaling factor has been recommended in other studies $[30,31,39]$. Three different partitions of mesh zones were defined for the thermomechanical model for LFW process. The partitions comprise of a structured fine mesh of element length $0.44 \mathrm{~mm}$, an unstructured mesh zone of element lengths 0.44 to $1.64 \mathrm{~mm}$ (constant biassing of 0.3 ) and a structure mesh region of coarsened mesh size of length $1.64 \mathrm{~mm}$ (see Fig. 1). A mesh dependency analysis was conducted by using welding process parameters for one LFW setup (process parameter set J6, details below). Figure 2 shows the outcome of mesh dependency analysis whereby the calculated maximum friction interface temperature is insensitive to using higher number of elements, especially when using more than 2500 elements.

\subsection{Microstructural model for $\delta$ phase}

In this study, the $\delta$ phase dissolution during rapid heating process of LFW was formulated by employing a timetemperature equivalence (TTE) model $[10,19,40]$. The material properties of IN718 alloy and $\delta$ phase were sourced from Yang [10]. The equilibrium volume fraction of the $\delta$ phase is given as $[10,19]$ :

$f_{\delta}(T)=\frac{X_{N b}-X_{N b, \gamma}(T)}{X_{N b, \delta}-X_{N b, \gamma}(T)}$

where $f_{\delta}(T)$ is the volume fraction of $\delta$ at temperature $T, X_{N b}$ is the atomic fraction of $\mathrm{Nb}$ in the alloy, $X_{N b, \gamma}(T)$ is the atomic fraction of $\mathrm{Nb}$ in the $\gamma$ matrix at temperature $T$ and $X_{N b, \delta}$ is the atomic fraction of $\mathrm{Nb}$ in the $\delta$ phase. The size and volume fraction of IN718 spherical $\delta$ phase prior to dissolution are $\sim 0.54 \mu \mathrm{m}$ and $0.95 \%$, respectively [10]. Equation 8 is based on the assumption that related phases are in thermodynamic equilibrium. During LFW process, however, the phases are not in thermodynamic equilibrium due to the high heating rate. Precipitate dissolution behaviour during rapid heating process differs from equilibrium dissolution [10, 19, 41]. In the TTE model, the thermal cycle with a heating rate $V_{h}$ from the initial temperature $T_{0}$ at time $t_{0}$ to the maximum temperature $T_{p}$ at time $t_{p}$ and with cooling rate $V_{c}$ (from $T_{p}$ at $t_{p}$ ) to $T_{0}$ at $t_{f}$ was replaced by an equivalent hold time $t_{e}$ at maximum temperature $T_{p}$. The variable $t_{e}$ is the sum of equivalent heating time $t_{e h}$ and the equivalent cooling time $t_{e c}$, which may be expressed as $[10,19]$ :

$t_{e}=t_{e h}+t_{e c}=\frac{R T_{p}^{2}}{Q}\left(\frac{1}{V_{h}}+\frac{1}{V_{c}}\right)$

where $R$ is gas constant and $Q$ activation energy for dissolution of $\delta$ phase. The $\delta$ phase diffusive field extends a distance of $y=\sqrt{D_{p} t_{e}}+r$ into the $\gamma$ matrix, where $D_{p}$ is the diffusion coefficient of $\mathrm{Nb}$ in $\mathrm{Ni}$ that is associated with the maximum temperature and $r$ is the radius of the spherical $\delta$ phase. Hence, the matrix volume fraction $f_{m}$ that is affected by dissolution is expressed as $[10,19]$ :

$$
y=\left\{\begin{array}{cc}
\sqrt{D_{p} t_{e}}+r<1 & f_{m}=\frac{\left(\sqrt{D_{p} t_{e}}+r\right)^{3}}{l^{3}} \\
\sqrt{D_{p} t_{e}}+r>1 & f_{m}=\frac{\left(\sqrt{D_{p} t_{e}}+r\right)^{3}}{\left(\sqrt{D_{p} t_{e}}+r\right)^{3}+l^{3}}
\end{array}\right.
$$

The variation of the atomic fraction of $\mathrm{Nb}$ in the $\gamma$ matrix $X_{N b, \gamma}(T)$ is substituted by a variable $X_{N b, \gamma}(T, t)$ related to the hold time $t$ at temperature $T$, given as [19]:

$X_{N b, \gamma}(T, t)-X_{N b, \gamma}=k\left((\sqrt{D t}+r)^{3}-r^{3}\right)$

where $k$ is a constant that is independent of $T$ and $t, D$ is the diffusion coefficient of $\mathrm{Nb}$ in $\mathrm{Ni}$ at a specific temperature $T$ and $r$ is the radius of the $\delta$ phase. $X_{N b, \gamma}$ is the atomic fraction of $\mathrm{Nb}$ in the $\gamma$ matrix before $\delta$ dissolution. The variation of $\mathrm{Nb}$ concentration in the $\gamma$ matrix around the precipitates is not considered. At the start of dissolution, $r=0.54 \mu \mathrm{m}$. At the temperature of complete $\delta$ dissolution $T_{c}$ and equivalent hold time $t_{c}$ during LFW process, $r=0$. So $k$ can be expressed as:

$k=\frac{X_{N b, \gamma}\left(T_{c}, t_{c}\right)-X_{N b, \gamma}}{\left(\sqrt{D_{c} t_{c}}+r\right)^{3}}$ 
Fig. 3 Flowchart of the integrated multiphysics computational modelling for LFW. The white coloured shapes represent the thermomechanical submodel, and the grey coloured shapes represent the microstructural submodel

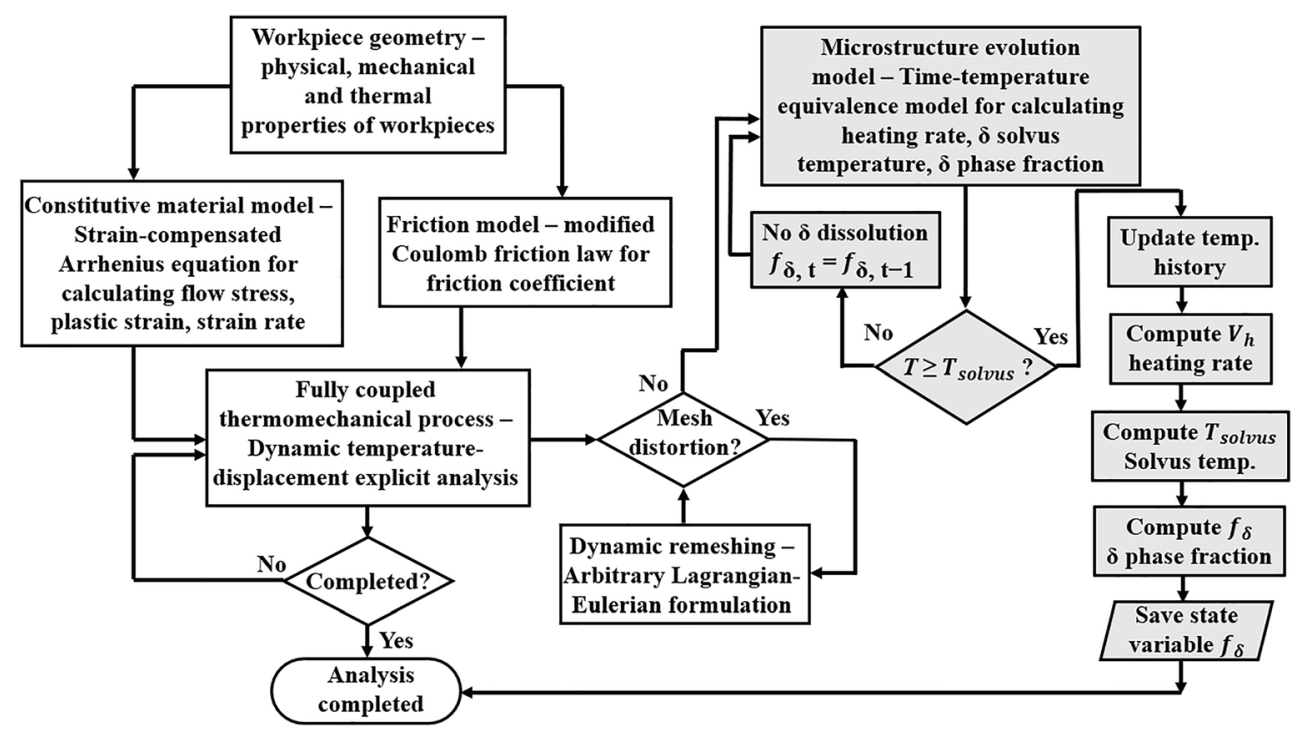

The volume fraction of the $\delta$ phase in the rapid heating process of LFW is expressed as:

$$
f_{\delta}(T)=\frac{X_{N b}-X_{N b, \gamma}-\left(\frac{X_{N b, \gamma}\left(T_{c}, t_{c}\right)-X_{N b, \gamma}}{\left(\sqrt{D_{c} t_{c}}+r\right)^{3}} \cdot\left(\left(\sqrt{D_{p} t_{e}}+r\right)^{3}-r^{3}\right)\right)}{X_{N b, \delta}-X_{N b, \gamma}-\left(\frac{X_{N b, \gamma}\left(T_{c}, t_{c}\right)-X_{N b, \gamma}}{\left(\sqrt{D_{c} t_{c}}+r\right)^{3}} \cdot\left(\left(\sqrt{D_{p} t_{e}}+r\right)^{3}-r^{3}\right)\right)}
$$

where $X_{N b, \gamma}$ is the atomic fraction of $\mathrm{Nb}$ in the $\gamma$ phase before $\delta$ phase dissolution. The computation for phase fraction of $\delta$ phase using Equations 9, 10, 11, 12 and 13 was implemented by running computations using Abaqus/Explicit solver in conjunction with the authors' VUSDFLD subroutine. In the research by Yang, the TTE model analysis used three different levels of constant heating rate, such as $1{ }^{\circ} \mathrm{C} / \mathrm{s}, 300^{\circ} \mathrm{C} / \mathrm{s}$ and $700{ }^{\circ} \mathrm{C} / \mathrm{s}$ [10]. However, in the actual LFW process, heating rate is not a constant but a variable that varies during the welding process. In the integrated multiphysics computational modelling of LFW, the actual heating rate was calculated as:
$V_{h}=\frac{T_{n}-T_{(n-1)}}{t_{n}-t_{(n-1)}}$

where $V_{h}$ is heating rate and $T_{n}$ and $T_{(n-1)}$ are the current temperature at increment $n$ and previous temperature at increment $(n-1)$ of thermomechanical modelling. The current time at increment $n$ and the time at previous increment ( $n$ $-1)$ are represented using $t_{n}$ and $t_{n-1}$. In this study, it was found that the heating rate could vary in the range of $0.01 \leq$ $V_{h} \leq 903.4{ }^{\circ} \mathrm{C} / \mathrm{s}$ during the LFW process depending on the process parameters. In the microstructural modelling, it was assumed that the IN718 alloy had $\delta$ phase volume fraction of $0.95 \%$ before the start of LFW.

\subsection{Model integration}

The flowchart in Fig. 3 shows how the integrated multiphysics computational modelling works as well as the sequential
Table 1 Process parameters applied in LFW computational modelling

\begin{tabular}{lllll}
\hline $\begin{array}{l}\text { Number of } \\
\text { weld }\end{array}$ & $\begin{array}{l}\text { Friction pressure } \\
p_{f}(\mathrm{MPa})\end{array}$ & $\begin{array}{l}\text { Oscillating } \\
\text { frequency } f_{0}(\mathrm{~Hz})\end{array}$ & $\begin{array}{l}\text { Oscillating amplitude } \\
A_{0}(\mathrm{~mm})\end{array}$ & $\begin{array}{l}\text { Specific heat input } Q_{S P I} \\
\left(\mathrm{~kW} \cdot \mathrm{m}^{-2}\right)\end{array}$ \\
\hline $\mathrm{J} 1$ & 200 & 15 & 2.5 & 1193.7 \\
$\mathrm{~J} 2$ & 200 & 25 & 2.9 & 2307.7 \\
$\mathrm{~J} 3$ & 200 & 25 & 3.5 & 2785.2 \\
$\mathrm{~J} 4$ & 300 & 25 & 2.9 & 3461.6 \\
$\mathrm{~J} 5$ & 300 & 25 & 3.5 & 4177.8 \\
$\mathrm{~J} 6$ & 400 & 25 & 2.9 & 4615.5 \\
$\mathrm{~J} 7$ & 400 & 25 & 2.5 & 5570.4 \\
$\mathrm{~J} 8$ & 400 & 30 & 2.5 & 5538.6 \\
$\mathrm{~J} 9$ & 500 & 15 & 2.9 & 2984.2 \\
$\mathrm{~J} 10$ & 500 & 25 & & 5769.4 \\
\hline
\end{tabular}


Table 2 LFW input process parameters for thermomechanical modelling setup [23]

\begin{tabular}{llll}
\hline Input parameters of modelling & \multicolumn{3}{c}{ Material properties } \\
\hline Heat partition coefficient & 0.5 & Density $\rho\left(\mathrm{kg} / \mathrm{m}^{3}\right)$ & 8420 \\
Friction energy change to heat & 0.9 & Elastic modulus $E(\mathrm{MPa})$ & 221000 \\
Mean friction coefficient & $0.01-0.60$ & Poisson's ratio $v$ & 0.3 \\
Shear stress limit & $60-100$ & Weld temperature $T\left({ }^{\circ} \mathrm{C}\right)$ & $25-1300$ \\
Welding process parameter & & Conductivity $\lambda(\mathrm{W} / \mathrm{m} / \mathrm{K})$ & $0.016 T+16.668$ \\
Oscillating amplitude $A_{0}(\mathrm{~mm})$ & $2.5-3.5$ & Specific heat $c_{p}(\mathrm{~J} / \mathrm{kg} / \mathrm{K})$ & $0.33 T+452.09$ \\
Oscillating frequency $f_{0}(\mathrm{~Hz})$ & $15-30$ & Expansion $\alpha_{w}\left(1 /{ }^{\circ} \mathrm{C}\right)$ & $4 * 10^{-9} T+10^{-5}$ \\
Friction pressure $p_{f}(\mathrm{MPa})$ & $200-500$ & Inelastic heat fraction & 0.9 \\
Axial shortening $L_{a}(\mathrm{~mm})$ & $1.0-7.5$ & Melting temperature $\left({ }^{\circ} \mathrm{C}\right)$ & 1300 \\
\hline
\end{tabular}

coupling between the thermomechanical model and the microstructural model.

\subsection{Process parameters of LFW and material properties}

In total, 10 different process parameter sets for LFW were defined (see Table 1). They include friction pressure $p_{f}$, oscillating amplitude $A_{0}$ and oscillating frequency $f_{0}$. These 10 different LFW setups were used as the background of computational modelling for systematically predicting the influence of process parameters on weld temperature and $\delta$ phase fraction of IN718 LFW. The specific heat input $Q_{S P I}$ can be approximately estimated as [42]:

$Q_{S P I}=\frac{p_{f} f_{0} A_{0}}{2 \pi}$

The material properties of IN718 are assumed to be isotropic and homogeneous, with temperature-dependent material property data sourced from [23]. Other material properties and LFW input process parameters can be found in Table 2 . Table 3 summarises the chemical composition of IN718 [5].

\section{Results and discussion}

\subsection{Temperature evolution}

Thermal history and maximum friction interface temperature are important indicators of the quality of LFWs in terms of desirable material microstructure and optimal mechanical properties. Figure 4 shows eight sampling points (A, B, C,

Table 3 Chemical composition of wrought IN718 in mass percentage [5]

\begin{tabular}{llllllll}
\hline $\mathrm{Cr}$ & $\mathrm{Mo}$ & $\mathrm{Nb}$ & $\mathrm{Al}$ & $\mathrm{Ti}$ & $\mathrm{Fe}$ & $\mathrm{C}$ & $\mathrm{Ni}$ \\
\hline 19 & 3 & 5.1 & 0.5 & 0.9 & 18.5 & 0.04 & 52.96 \\
\hline
\end{tabular}

$\mathrm{D}, \mathrm{E}, \mathrm{F}, \mathrm{G}$ and $\mathrm{H}$ ) either on the friction interface or on the right side of the bottom workpiece at the start of welding (not drawn to scale). They are $2 \mathrm{~mm}$ apart before welding starts, although during welding, each point can get displaced further away from adjacent sampling points because of the deformation of the weld.

Figure 5 presents the computational modelling results of temperature at sampling points $\mathrm{A}, \mathrm{B}, \mathrm{C}$ and $\mathrm{E}$ (as shown in Fig. 4) for the LFW setup J6. There are four stages of LFW, including initial/contact stage, transition stage, equilibrium stage and extrusion/deceleration stage [1]. These stages occur at varying welding times depending on the configuration of

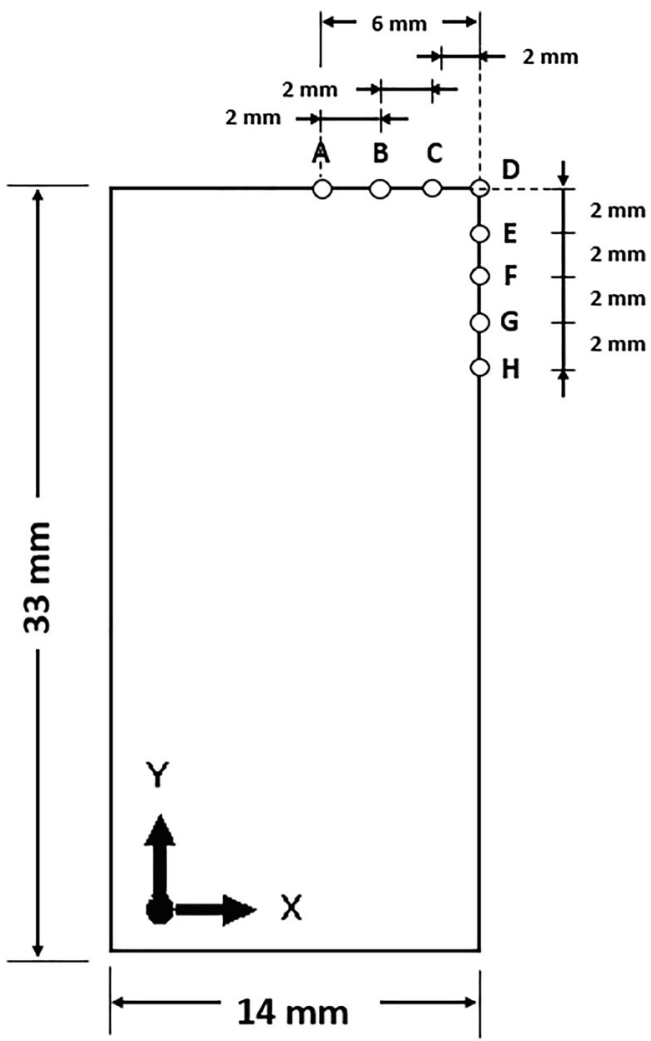

Fig. 4 Geometry of the bottom workpiece of LFW and the position of eight sampling points (A, B, C, D, E, F, G and H) identified on the friction interface and right side of the bottom workpiece in $2 \mathrm{D}$ 


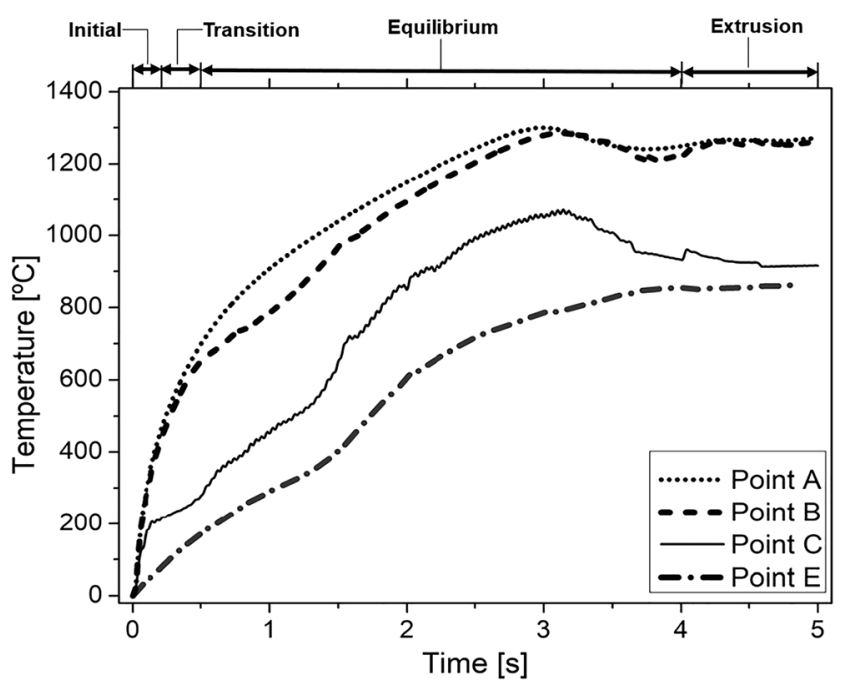

Fig. 5 Temperature histories of the bottom workpiece at sampling points A, B, C and E for LFW setup J6

welding process parameters and resultant material response during LFW [43, 44]. The initial stage is a brief stage at the start of LFW when workpieces first contact each other under friction pressure. In the transition stage, there is full surface contact with asperities, while the equilibrium stage indicates the absence of asperities and softening of friction interface material. Friction pressure is usually at maximum value during the extrusion/deceleration stage also accompanied by flash formation $[2,44]$.

In Fig. 5, the maximum temperature at sampling points $\mathrm{A}$, $\mathrm{B}, \mathrm{C}$ and $\mathrm{E}$ is $1301.2^{\circ} \mathrm{C}, 1288.6^{\circ} \mathrm{C}, 1072.4^{\circ} \mathrm{C}$ and $870.2^{\circ} \mathrm{C}$, respectively. These maximum temperature levels are lower than the liquidus temperature of IN718 $\left(\sim 1360^{\circ} \mathrm{C}\right)$ and were attained in the equilibrium stage of LFW. Sampling point A is shown to have the highest temperature; it is exactly at the midregion of the friction interface. Sampling points B, C and E show lower levels of temperature compared to sampling point $\mathrm{A}$, and these three points are further away from the mid-region of the friction interface. The maximum temperature was reached at $3.2 \mathrm{~s}$ of welding for sampling points $\mathrm{A}, \mathrm{B}$ and $\mathrm{C}$, while the maximum temperature was reached at $5.0 \mathrm{~s}$ of welding for sampling point $\mathrm{E}$. After reaching maximum temperature, the subsequent change in temperature value is $\pm 45^{\circ}$ $C$ of the maximum temperature for sampling points A, B and $\mathrm{C}$ as shown in Fig. 5. Overall, after a process of very rapid increase in temperature, the weld temperature gradually evolves towards a plateau value during the equilibrium stage and extrusion stage of LFW.

Overall, the workpiece has the highest level of temperature near the centre of its friction interface and has lower level of temperature away from the centre of friction interface. Qin et al. and Okeke et al. have likewise identified varying temperature levels at different positions on the weld interface of this type $[23,29]$. A similar phenomenon can be found for sampling points $\mathrm{D}, \mathrm{F}, \mathrm{G}$ and $\mathrm{H}$. As the sampling points $\mathrm{D}, \mathrm{F}, \mathrm{G}$ and $\mathrm{H}$ are progressively spaced $2 \mathrm{~mm}$ from the friction interface, along the right side of the bottom workpiece, there is decreasing level of temperature.

The temperature contour for different friction times (between 1.0 and $5.0 \mathrm{~s}$ of LFW setup J6) can be found in Fig. 6 . The figure shows a narrow area of high thermal gradient near the friction interface during the overall process of LFW. During LFW, the contacting workpieces rapidly rub against each other under large compressive force, thus transforming kinetic energy to thermal energy. Heat is generated at the weld interface and subsequently conducted to other places of the weld. This is very clear difference in the temperature field between 1.0 and $3.0 \mathrm{~s}$ of LFW (see Fig. 6). The change of temperature contour in the weld between 3.0 and $5.0 \mathrm{~s}$ is comparatively less pronounced and commonly described as
Fig. 6 Evolution of temperature field at the weld joint during LFW process for setup $\mathrm{J} 6$ where $\mathrm{p}_{\mathrm{f}}=$ $400 \mathrm{MPa}, \mathrm{f}_{0}=25 \mathrm{~Hz}$ and $\mathrm{A}_{0}=$ $2.9 \mathrm{~mm}$
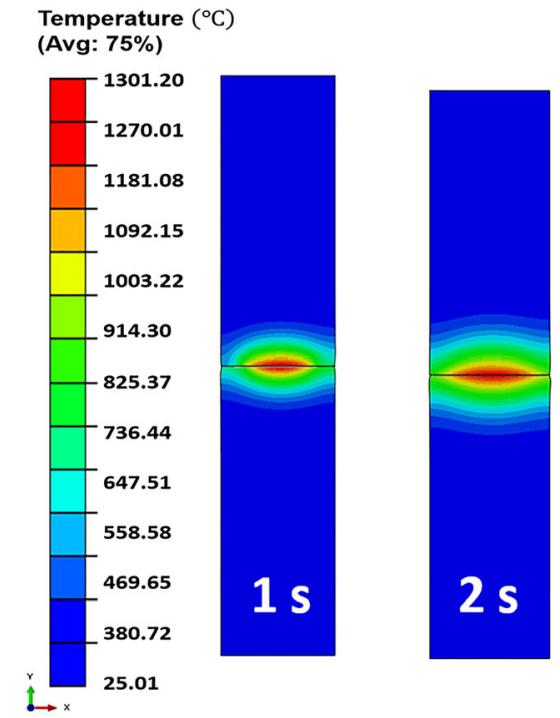
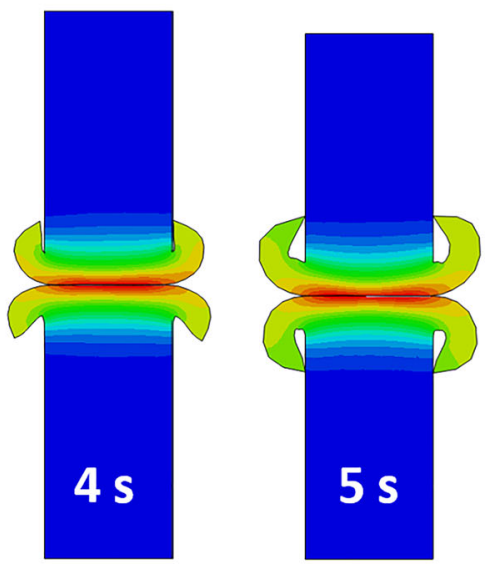
Fig. 7 Evolution of Mises stress at the weld joint during LFW process for setup J6 where $p_{f}=$ $400 \mathrm{MPa}, f_{0}=25 \mathrm{~Hz}$ and $A_{0}=$ $2.9 \mathrm{~mm}$
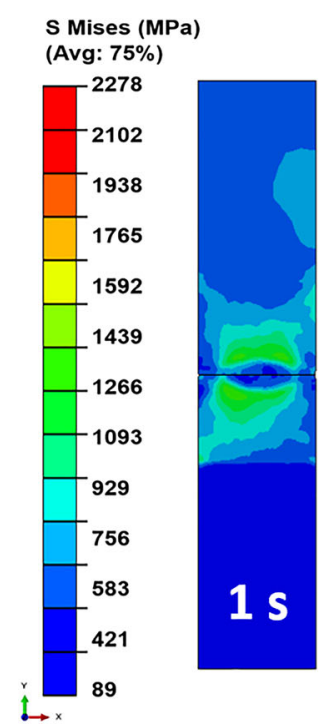
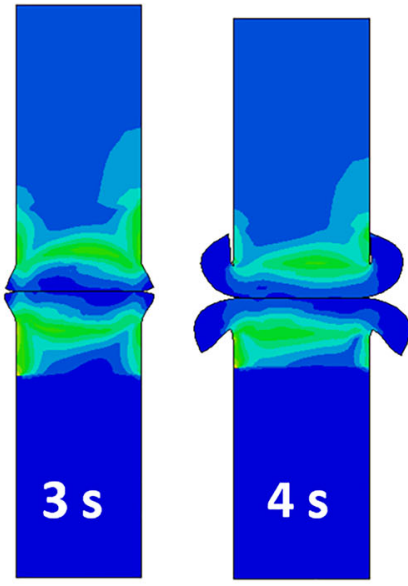

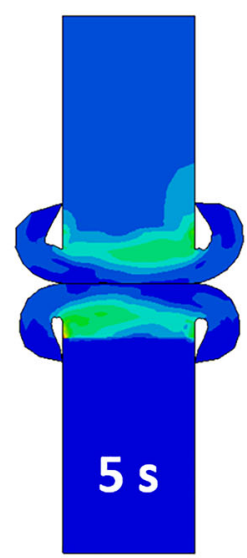

the quasi-steady-state behaviour of IN718 during LFW [23, 32]. Considerable thermal softening of material near the friction interface can be seen between friction time of $3.0 \mathrm{~s}$ and $5.0 \mathrm{~s}$, as shown in Fig. 6. Flash formation and axial shortening of the weld happened, while the material near the friction interface got significantly heated and softened by friction heat.

\subsection{Mises stress and plastic strain fields}

Figures 7 and 8 show the modelling results of von Mises stress and equivalent plastic strain and their evolution with time during LFW process for setup J6. At $1.0 \mathrm{~s}$ of welding, the maximum Mises stress is $1592 \mathrm{MPa}$, and the equivalent plastic strain is 6.04 . At $2.0 \mathrm{~s}$ of welding, no significant deformation of material occurs yet, and maximum Mises stress and plastic strain are $1611 \mathrm{MPa}$ and 7.32, respectively. Up to $3.0 \mathrm{~s}$ of welding time, the maximum Mises stress reduces to 421
$\mathrm{MPa}$, and the maximum plastic strain increases to 7.37. This decrease in maximum stress during LFW refers to the quasisteady-state behaviour of IN718, whereby increasing temperature at the friction interface does not increase the Mises stress field $[23,32]$. The overall plastic deformation at the interface is initially driven by friction heat, which is later replaced by plastic work as the driving force of plastic deformation at thermal equilibrium $[22,23]$. Based on this computational modelling result, it can be concluded that this stage of thermal equilibrium happens at welding time of 3.2 to $4.5 \mathrm{~s}$ for LFW setup J6. The extrusion stage of welding (between 4.0 and 5.0 s) shows a maximum plastic strain $(\sim 7.37)$ on the periphery of the friction interface for the top and bottom workpieces. Shearing and extrusion are the two principal modes of deformation influencing the stress and strain distribution during LFW of IN718 [22, 23, 32].
Fig. 8 Evolution of equivalent plastic strain during LFW process for setup $\mathrm{J} 6$ where $p_{f}=400 \mathrm{MPa}$, $f_{0}=25 \mathrm{~Hz}$ and $A_{0}=2.9 \mathrm{~mm}$
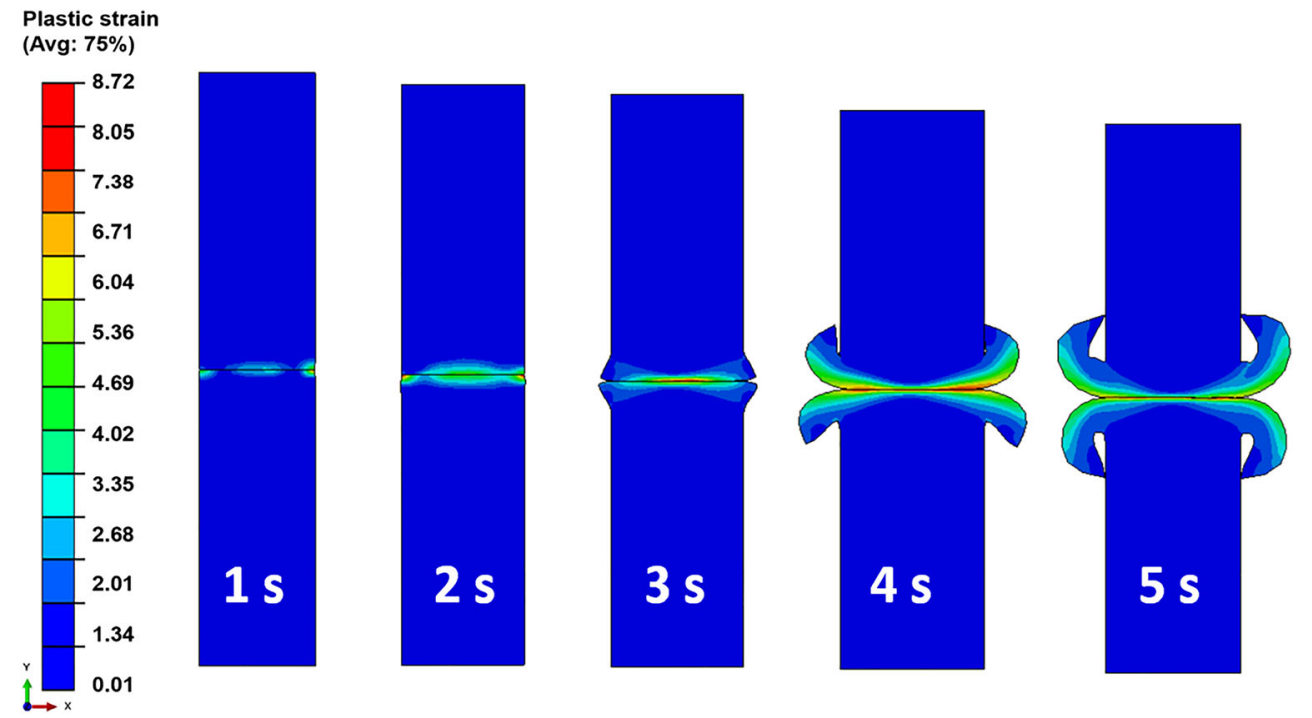


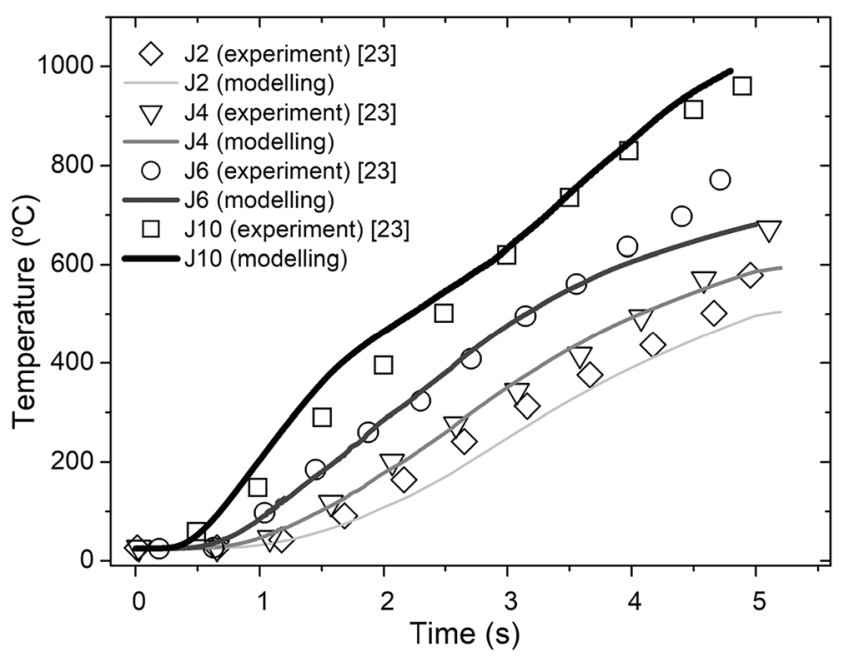

Fig. 9 Comparison of experimentally measured results of temperature (experiment) of Qin et al. and computational modelling results of temperature (modelling) for LFW setups J2, J4, J6 and J10 [23]

\subsection{Verification of thermomechanical modelling}

\subsubsection{Temperature history}

The modelling results of temperature for LFW setups J2, J4, $\mathrm{J} 6$ and $\mathrm{J} 10$ (see Table 1) were compared with the result of experimental measurements by Qin et al. for the same alloy and the same setup of LFW process [23]. The modelling results of temperature were sampled at $5 \mathrm{~mm}$ away from the friction interface, which was how Qin et al. measured the temperature evolution of their welds during LFW using thermocouples [23]. As can be found in Fig. 9, the modelling results of temperature agree well with corresponding results of experimental measurement of Qin et al.

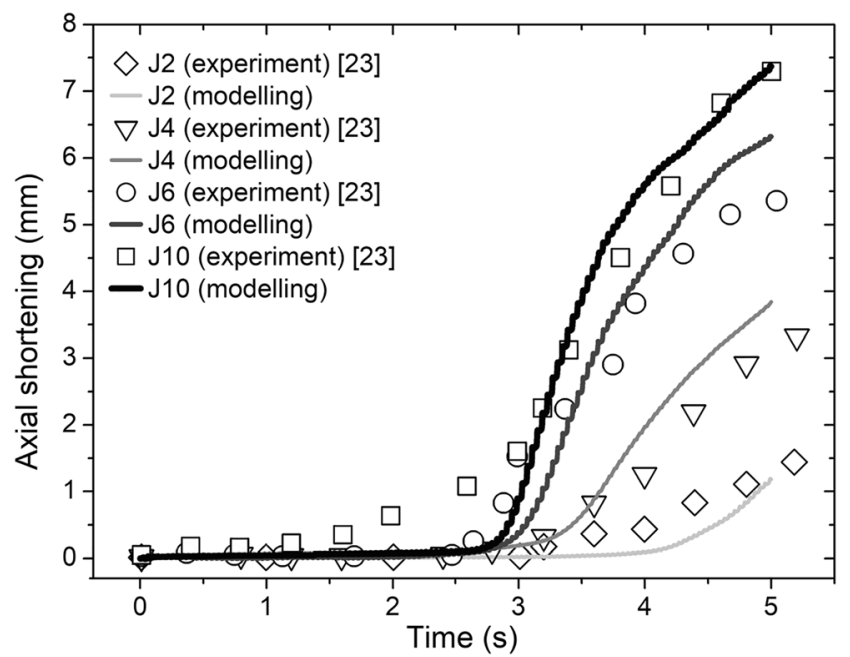

Fig. 10 Comparison of computational modelling results of axial shortening (modelling) with experimentally measured results (experiment) of Qin et al. for LFW time of $5.0 \mathrm{~s}$ based on setups J2, J4, $\mathrm{J} 6$ and $\mathrm{J} 10$ [23]

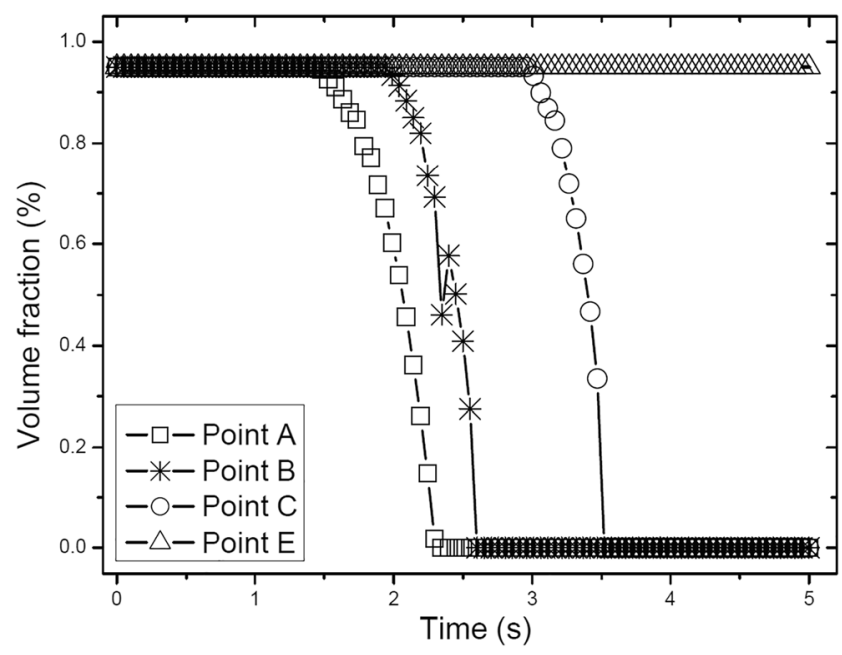

Fig. 11 Evolution of $\delta$ phase volume fraction of the bottom workpiece sampling points A, B, C and E for LFW setup J6

\subsubsection{Macrostructural features: flash shape and axial shortening}

Flash formation and axial ( $y$-axis) shortening are important indicators of LFW weld integrity. Geng et al. measured the axial shortening of LFW setups $\mathrm{J} 2, \mathrm{~J} 4, \mathrm{~J} 6$, J8 and $\mathrm{J} 10$ as $1.6 \pm$ $0.2 \mathrm{~mm}, 2.3 \pm 0.3 \mathrm{~mm}, 4.8 \pm 0.2 \mathrm{~mm}, 5.1 \pm 0.3 \mathrm{~mm}$ and $6.8 \pm$ $0.4 \mathrm{~mm}$, respectively [11]. The computational modelling results of axial shortening by the authors are $1.18 \mathrm{~mm}, 1.72 \mathrm{~mm}$, $3.84 \mathrm{~mm}, 6.32 \mathrm{~mm}$ and $7.84 \mathrm{~mm}$ for setups $\mathrm{J} 2, \mathrm{~J} 4, \mathrm{~J} 6, \mathrm{~J} 8$ and $\mathrm{J} 10$, respectively. As shown in Fig. 10, the modelling results of axial shortening agree well with corresponding experimental results of Qin et al. [23]. Flash formation has self-cleaning effect, and axial shortening can improve joint integrity [11, 45]. A critical axial shortening of $l_{a} \geq(4.8 \pm 2) \mathrm{mm}$ was

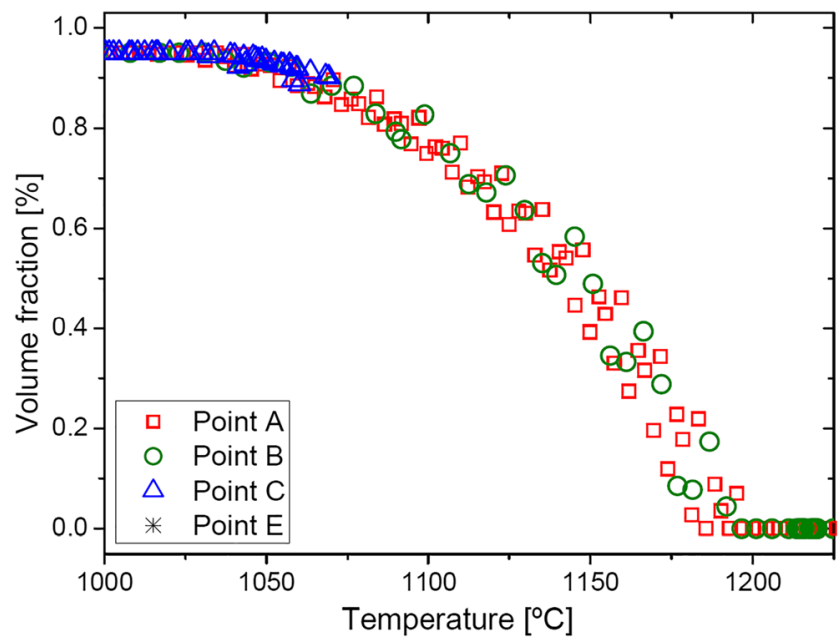

Fig. 12 Evolution of $\delta$ phase volume fraction with temperature at sampling points $\mathrm{A}, \mathrm{B}, \mathrm{C}$ and $\mathrm{E}$ during the $\mathrm{LFW}$ process corresponding to setup J6 
recommended by Geng et al. to achieve a sound joint free of oxides at the interface [11]. In the current study, LFW setups $\mathrm{J} 6$ and $\mathrm{J} 10$ indicated axial shortening of $6.3 \mathrm{~mm}$ and $7.5 \mathrm{~mm}$, respectively, thus satisfying the recommended critical axial shortening. Comprehensive modelling results of the thermomechanical processes of LFW can be found in a paper previously published by the authors [29]. The thermomechanical modelling results are only briefly presented in this paper in order to facilitate the analysis of the influence of thermomechanical process on material microstructural evolution during LFW.

\subsection{Microstructural evolution of weld and model verification}

Figure 11 shows the computational modelling results of temporal evolution of $\delta$ phase volume fraction at sampling points A, B, C and E. $\delta$ phase volume fraction is $0.95 \%$ between welding time of $0.0 \mathrm{~s}$ and $1.0 \mathrm{~s}$ at all four sampling points. There is no $\delta$ phase dissolution at welding time of $1.0 \mathrm{~s}$ yet because the temperature at $1.0 \mathrm{~s}$ is below the $\delta$ phase equilibrium solvus temperature of $1010{ }^{\circ} \mathrm{C}$ (see Fig. 5). The $\delta$ phase volume fraction starts decreasing at welding time of $1.6 \mathrm{~s}$, $2.1 \mathrm{~s}$ and $3.1 \mathrm{~s}$ for sampling points A, B and C, respectively. $\delta$ phase dissolved completely at welding time of $2.3 \mathrm{~s}, 2.6 \mathrm{~s}$ and $3.5 \mathrm{~s}$ for sampling points A, B and C, respectively. Thus, the dissolution rate is higher for sampling points near the midregion of the friction interface than for sampling points further away from the mid-region of friction interface. The $\delta$ phase

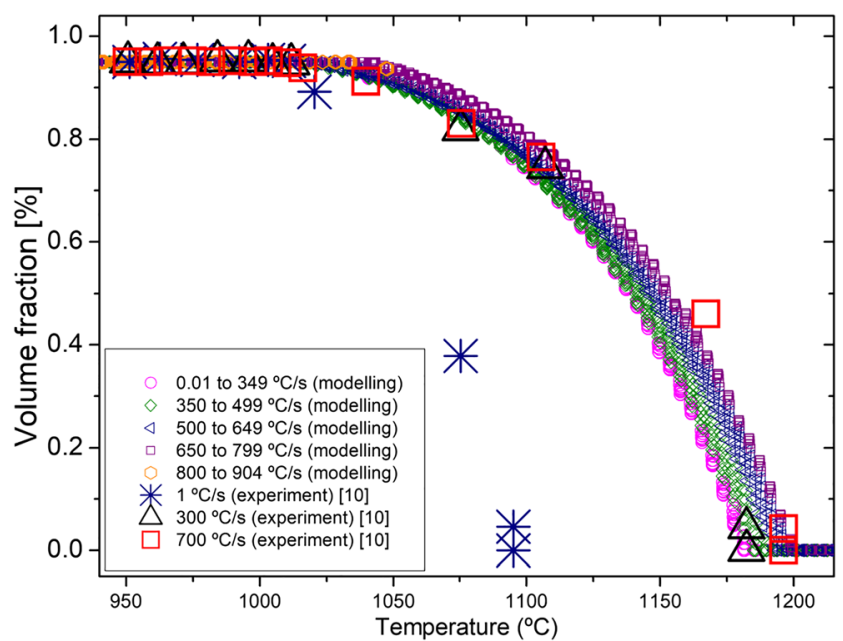

Fig. 13 Comparison of experimentally measured results of $\delta$ phase volume fraction (experiment) of Yang and microstructural modelling results of $\delta$ phase fraction (modelling) by the authors at sampling point $\mathrm{A}$ (on the friction interface) during LFW process of setup J6. The experimental results of Yang are for three different levels of constant heating rate of $1{ }^{\circ} \mathrm{C} / \mathrm{s}, 300{ }^{\circ} \mathrm{C} / \mathrm{s}$ and $700{ }^{\circ} \mathrm{C} / \mathrm{s}$, while the modelling results are grouped into five different bands of heating rate, which include 0.01 to $349{ }^{\circ} \mathrm{C} / \mathrm{s}, 350$ to $499{ }^{\circ} \mathrm{C} / \mathrm{s}, 500$ to $649{ }^{\circ} \mathrm{C} / \mathrm{s}, 650$ to $799{ }^{\circ} \mathrm{C} / \mathrm{s}$ and 800 to $904^{\circ} \mathrm{C} / \mathrm{s}[10]$

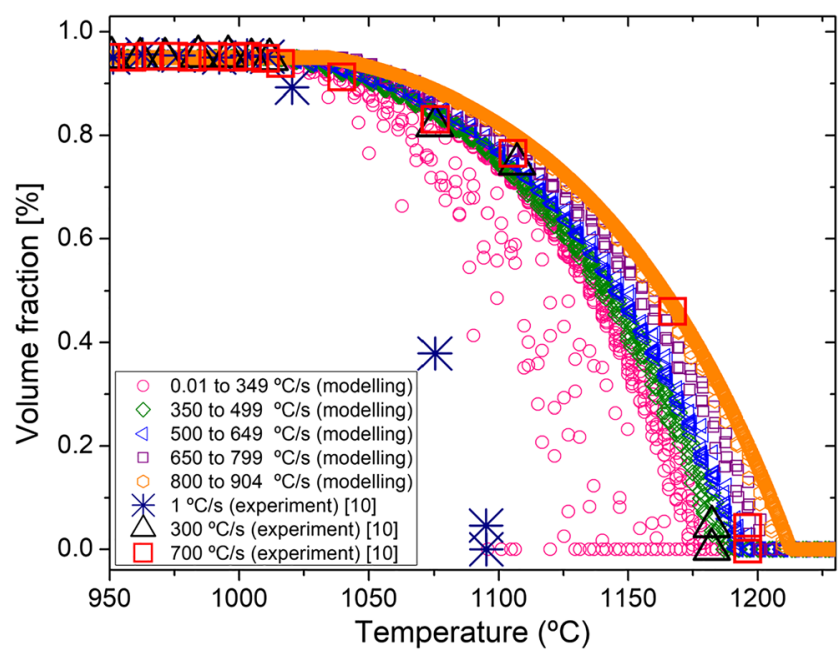

Fig. 14 Comparison of experimentally measured results of $\delta$ phase volume fraction (experiment) of Yang and microstructural modelling results of $\delta$ phase fraction (modelling) by the authors at sampling point $\mathrm{A}$ (on the friction interface) during LFW process of setup J8. The experimental results of Yang are for three different levels of constant heating rate of $1{ }^{\circ} \mathrm{C} / \mathrm{s}, 300{ }^{\circ} \mathrm{C} / \mathrm{s}$ and $700{ }^{\circ} \mathrm{C} / \mathrm{s}$, while the modelling results are grouped into five different bands of heating rate, which include 0.01 to $349^{\circ} \mathrm{C} / \mathrm{s}, 350$ to $499^{\circ} \mathrm{C} / \mathrm{s}, 500$ to $649{ }^{\circ} \mathrm{C} / \mathrm{s}, 650$ to $799^{\circ} \mathrm{C} / \mathrm{s}$ and 800 to $904^{\circ} \mathrm{C} / \mathrm{s}[10]$

volume fraction of sampling point $\mathrm{E}$ did not change during LFW, indicating that the maximum temperature for point $\mathrm{E}$ did not reach the $\delta$ phase equilibrium solvus temperature of $1010^{\circ} \mathrm{C}$. The $\delta$ phase volume fraction remained $0.95 \%$ during LFW for all sampling points positioned on the right-hand side of the bottom workpiece.

Figure 12 shows the microstructural modelling results of the evolution of $\delta$ phase volume fraction with temperature at four sampling points (A, B, C and E) for setup J6 during LFW process. It can be seen that the $\delta$ phase volume fraction decreases nonlinearly with increasing temperature for sampling points A and B. $\delta$ phase completely dissolves at the temperature between 1182 and $1223{ }^{\circ} \mathrm{C}$. Sampling point $\mathrm{C}$ shows partial $\delta$ phase dissolution up to $1070{ }^{\circ} \mathrm{C}$. No $\delta$ phase dissolution occurred at sampling point $\mathrm{E}$ because the maximum temperature at point $\mathrm{E}$ is $903.2{ }^{\circ} \mathrm{C}$, which is considerably below $1010{ }^{\circ} \mathrm{C}$ ( $\delta$ phase equilibrium solvus temperature). The equilibrium dissolution of $\delta$ phase starts at $\sim 1010{ }^{\circ} \mathrm{C}$ and completes at $\sim 1070{ }^{\circ} \mathrm{C}[10]$. However, the actual solvus temperature can be higher than $1070{ }^{\circ} \mathrm{C}$ for a rapid continuous heating process like LFW, thereby shifting the $\delta$ phase dissolution to a higher level of temperature as heating rate increases, as found in multiple studies $[10,19,20]$.

The microstructural modelling of $\delta$ phase - in terms of volume fraction and spatial distribution - can be verified by comparing the microstructural modelling results with related experimental results of Yang [10]. The microstructural modelling of $\delta$ phase volume fraction was completed for LFW setups $\mathrm{J} 6$ and $\mathrm{J} 8$, and the computational results of evolution 
of $\delta$ phase volume fraction with temperature at sampling points A are displayed in Figs. 13 and 14. In Figs. 13 and 14 , experimental results of Yang for $\delta$ phase volume fraction are presented at three different levels of constant heating rate including of $1{ }^{\circ} \mathrm{C} / \mathrm{s}, 300^{\circ} \mathrm{C} / \mathrm{s}$ and $700{ }^{\circ} \mathrm{C} / \mathrm{s}$, and their respective $\delta$ phase solvus temperature values are $1090{ }^{\circ} \mathrm{C}, 1182{ }^{\circ} \mathrm{C}$ and $1200{ }^{\circ} \mathrm{C}$ [10]. In the experimental research of Yang, Gleeble testing of IN718 alloy was completed at the related three different levels of constant heating rate [10]. In the practical LFW and in the thermomechanical modelling of LFW, the heating rate of weld is a variable that can vary significantly and continuously vary during LFW process, for example, as shown in Fig. 5. In the integrated computational modelling, the heating rate is computed by the thermomechanical submodel and used as one of the inputs of the microstructural submodel for computing the $\delta$ phase fraction. In order to compare the modelling results of $\delta$ phase volume fraction with the Gleeble testing results of Yang [10], the microstructural modelling results of $\delta$ phase volume fraction of this paper were grouped into different bands of heating rate such as 0.01 to $349{ }^{\circ} \mathrm{C} / \mathrm{s}$ and 350 to $449{ }^{\circ} \mathrm{C} / \mathrm{s}$ as shown in Figs. 13 and 14 . It can be seen that the microstructural modelling results of $\delta$ phase volume fraction agree well with corresponding experimental results by Yang [10].

Besides verifying the integrated multiphysics computational modelling, the modelling results shown in Figs. 13 and 14 can clearly show the influence of process parameters on $\delta$ phase evolution in the weld during LFW. Setup J8 uses higher level of energy input compared to setup J6 (see Table 1). It can be seen that in Fig. 13 (Setup J6), the scattered symbols representing modelling results of $\delta$ phase volume fraction mainly fall in the high heating rate bands $\left(350{ }^{\circ} \mathrm{C} / \mathrm{s}\right.$ and above). In Fig. 14 (Setup J8), however, many data points of the modelling results of $\delta$ phase volume fraction fall in the low

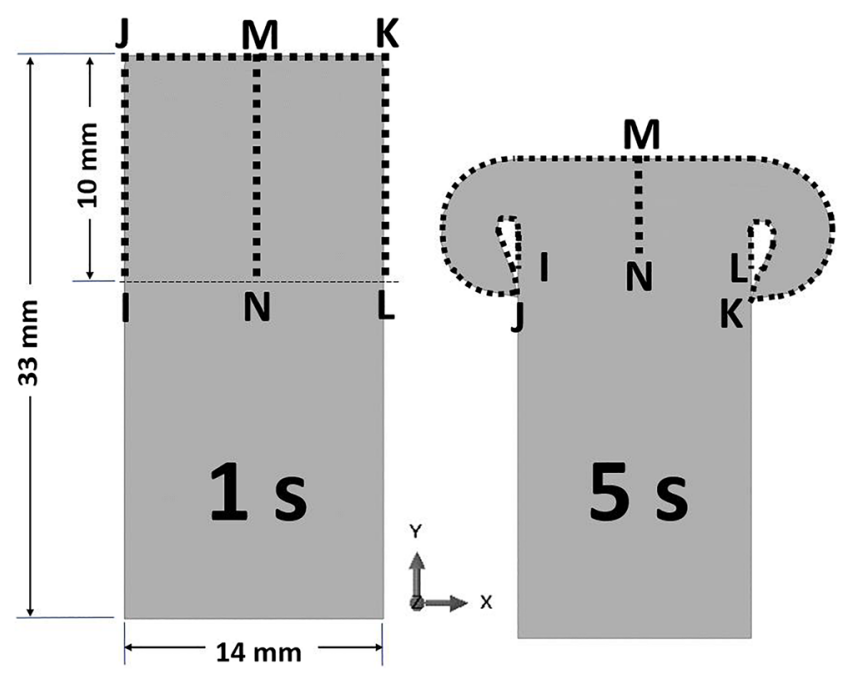

Fig. 15 Paths $\mathrm{M}-\mathrm{N}$ and $\mathrm{I}-\mathrm{J}-\mathrm{K}-\mathrm{L}, 10 \mathrm{~mm}$ and $34 \mathrm{~mm}$ long, respectively, at the surface of the bottom weld based on LFW setup J6

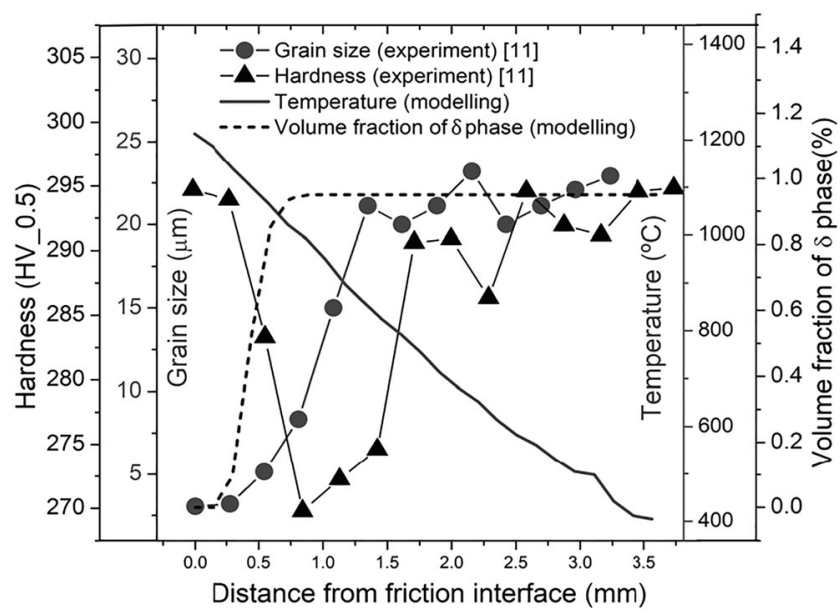

Fig. 16 Experimental results of profile of $\gamma$ grain size and weld hardness of LFW-IN718 of Geng et al. and integrated multiphysics computational modelling results of temperature and $\delta$ phase volume fraction along path $\mathrm{M}-\mathrm{N}$ based on LFW setup J6 at $5.0 \mathrm{~s}$ of welding [11]

heating rate band of $349{ }^{\circ} \mathrm{C} / \mathrm{s}$ and below. This implies that $\delta$ phase evolution experiences a wider range of heating rate for high-energy input setup (Setup J8) compared to the $\delta$ phase evolution in a low-energy input setup (Setup J6).

\subsection{Relationship between $\delta$ volume fraction, size of $\gamma$ grain and microhardness}

In this section of the paper, the modelling results of $\delta$ volume fraction is analysed along path $\mathrm{M}-\mathrm{N}(10 \mathrm{~mm}$ long $)$ and path $\mathrm{I}-$ $\mathrm{J}-\mathrm{K}-\mathrm{L}$ (34 mm long) as shown in Fig. 15, at the surface of the bottom weld based on LFW setup J6. The length of path M-N can get significantly reduced, and the length of path $\mathrm{I}-\mathrm{J}-\mathrm{K}-\mathrm{L}$ can get significantly increased because of axial shortening and flash formation of weld during LFW process as shown in Fig.

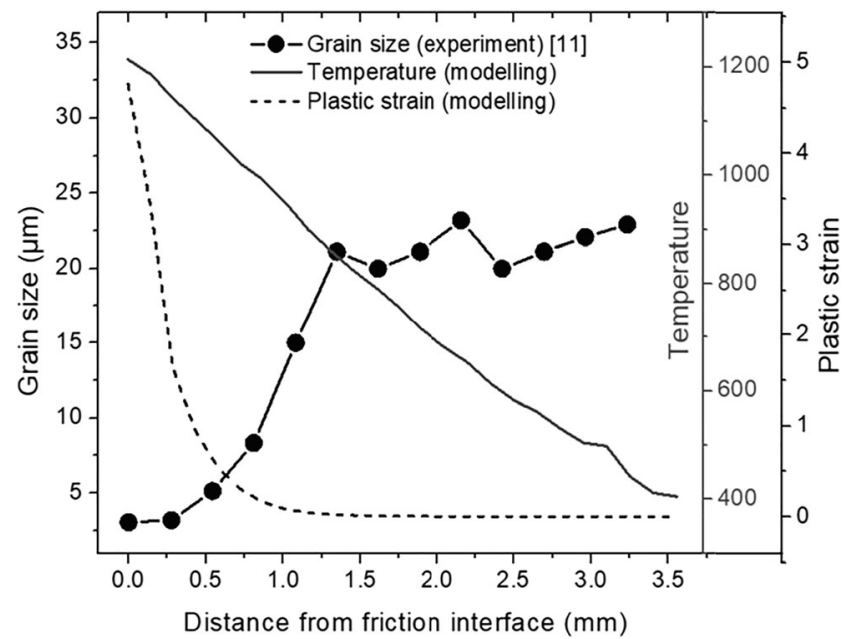

Fig. 17 Experimental result of profile of $\gamma$ grain size of LFW-IN718 of Geng et al. and computational modelling results of profile of temperature and plastic strain along a sampling path $\mathrm{M}-\mathrm{N}$ based on LFW setup $\mathrm{J} 6$ at $5.0 \mathrm{~s}$ of welding [11] 
15. In this paper, the direction of path $\mathrm{M}-\mathrm{N}$ is always from $\mathrm{M}$ to $\mathrm{N}$, and the direction of path $\mathrm{I}-\mathrm{J}-\mathrm{K}-\mathrm{L}$ is always from $\mathrm{I}$ to $\mathrm{J}, \mathrm{J}$ to $\mathrm{K}$ and $\mathrm{K}$ to $\mathrm{L}$. The path $\mathrm{I}-\mathrm{J}-\mathrm{K}-\mathrm{L}$ is not separated but a continuous path identified on the bottom workpiece.

As shown in Fig. 16, the profile of $\delta$ phase volume fraction, temperature, size of $\gamma$ grain and microhardness of weld is analysed along path $\mathrm{M}-\mathrm{N}$ of the bottom workpiece for LFW setup J6 at $5.0 \mathrm{~s}$ of welding. The profile of $\delta$ phase volume fraction and temperature is a result of the integrated computational modelling of this paper. The profile of $\gamma$ grain size and microhardness of weld is an experimental result of Geng et al. for IN718 LFW using the setup J6 [11]. Overall, the $\delta$ phase volume fraction increases from the friction interface towards the base metal (BM), which is about $3.5 \mathrm{~mm}$ relative to the friction interface, along the path $\mathrm{M}-\mathrm{N}$. The increase in $\delta$ phase volume fraction is due to the decreasing temperature away from the friction interface towards the BM. By related experimental results of Geng et al., the weld hardness decreases from a maximum value of 295 (at the friction interface) to a minimum value of $270 \mathrm{HV}$ ( $1 \mathrm{~mm}$ away from the friction interface) [11]. Geng et al. identified the lowest value of weld hardness in the thermomechanically affected zone (TMAZ) and attributed the weld hardness profile to the combined influence of DRX and dissolution of strengthening phases [11]. The high level of material hardness at the friction interface is related to the refined $\gamma$ grains due to DRX.

In Fig. 17, the profile of $\gamma$ grain size, temperature and plastic strain is analysed along path $\mathrm{M}-\mathrm{N}$ of the bottom workpiece for LFW setup J6 at $5.0 \mathrm{~s}$ of welding. The profile of $\gamma$ grain size is the experimental result by Geng et al., and the profile of temperature and plastic strain is the result of the integrated multiphysics computational modelling of this paper [11]. At the friction interface, as shown in Fig. 17, there is very high level of temperature and strain. They facilitate significant DRX of $\gamma$ grains at the friction interface. The refined $\gamma$ grains result in high level of hardness at the friction interface. The $\gamma$ grain size increases with decreasing temperature and decreasing plastic strain towards the BM and reaches the BM value (the $\mathrm{BM}$ is $3.5 \mathrm{~mm}$ relative to friction interface and beyond). This finding is consistent with the experimental results of Mary and Jahazi that grain size measurements at distances greater than $3.0 \mathrm{~mm}$ from the friction interface remained constant and equal to that of the BM value [16].

The relationships between the integrated multiphysics computational modelling results of this paper and experimentally measured results from literature give some insight into the extent to which the LFW process can induce significant microstructural evolution in the IN718 welds. For example, the overall results presented in Figs. 16 and 17 illustrate how high temperature and high strain can induce DRX and $\delta$ phase dissolution, resulting to varying profiles of $\gamma$ grain size and hardness on the surface of the IN718 weld. DRX, dynamic recovery and dynamic phase dissolution are recognised mechanisms of microstructural evolution resulting from high temperature and high strain at the weld during LFW of IN718 $[10,11,46]$. Yang attributed the uneven hardness of IN718 welds to dissolution of strengthening phases during LFW [10]. However, Geng et al. found that dissolution of strengthening phases of IN718 is a secondary contributor to the increased hardness and decreased $\gamma$ grain size at the IN718 weld joint; DRX is primarily responsible for the increased hardness at the IN718 weld joint [11]. The integrated multiphysics computational modelling of this paper has shown through process-structure prediction capability that it can be used to predict and/or interpret how related thermomechanical processes can affect the material microstructure of LFW weld.

\subsection{Influence of LFW process parameters on properties of weld}

Figure 18 shows profile of temperature (identified with subscript ' $T$ ') and $\delta$ phase fraction (identified with subscript ' $p$ ') for each of paths $\mathrm{I}-\mathrm{J}, \mathrm{J}-\mathrm{K}$ and $\mathrm{K}-\mathrm{L}$ for LFW setup J6 at $5.0 \mathrm{~s}$ of welding. Although paths $\mathrm{I}-\mathrm{J}, \mathrm{J}-\mathrm{K}$ and $\mathrm{K}-\mathrm{L}$ have been separately identified using subscripts, the direction of path I-J$\mathrm{K}-\mathrm{L}$ is always from $\mathrm{I}$ to $\mathrm{J}, \mathrm{J}$ to $\mathrm{K}$ and $\mathrm{K}$ to $\mathrm{L}$. Each of paths $\mathrm{I}-\mathrm{J}$, $\mathrm{J}-\mathrm{K}$ and $\mathrm{K}-\mathrm{L}$ elongates during LFW because of weld deformation. In the Cartesian coordinate system of the 2D modelling of this paper, the centre of friction interface of the bottom workpiece is at $x=0$. The profiles of $\delta$ phase fraction along paths $\mathrm{I}-\mathrm{J}$ and $\mathrm{K}-\mathrm{L}$ show that no $\delta$ dissolution occurred at the side surface of weld because the maximum temperature $\left(872.488^{\circ} \mathrm{C}\right.$ ) is considerably below the $\delta$ phase equilibrium solvus temperature $\left(1010^{\circ} \mathrm{C}\right)$. However, $\delta$ phase fraction profile along path $\mathrm{J}-\mathrm{K}$ shows fully dissolved, partially dissolved and undissolved $\delta$ phase regions at $x=5 \mathrm{~mm}, 6 \mathrm{~mm}$ and $7 \mathrm{~mm}$, respectively, relative to the centre of friction interface. The

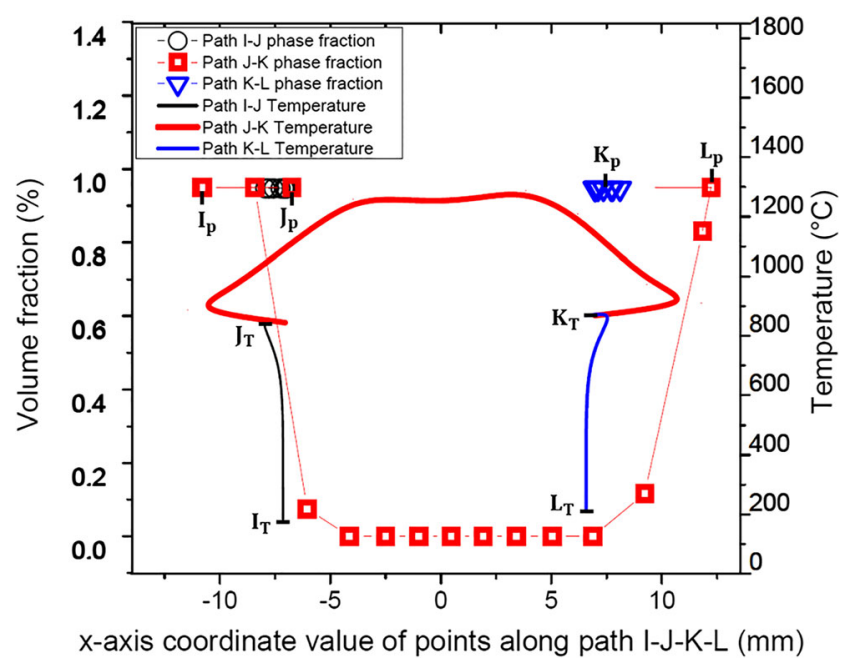

Fig. 18 Computational modelling results of profile of temperature and $\delta$ phase volume fraction along paths I-J, J-K and $\mathrm{K}-\mathrm{L}$ for LFW setup J6, with subscript ' $\mathrm{T}$ ' for temperature and subscript ' $\mathrm{p}$ ' for phase fraction 
corresponding temperature profile of path $\mathrm{J}-\mathrm{K}$ shows that in the fully dissolved, partially dissolved and undissolved $\delta$ phase regions, weld temperature is approximately 1231.89 ${ }^{\circ} \mathrm{C}, 1067.51{ }^{\circ} \mathrm{C}$ and $844.612{ }^{\circ} \mathrm{C}$, respectively. Thus, $\delta$ phase tends to dissolve in regions of very high temperature level.

Figure 19 a to $d$ illustrate the profiles of $\delta$ phase volume fraction and temperature along the path $\mathrm{I}-\mathrm{J}-\mathrm{K}-\mathrm{L}$ (see Fig. 15) at $5.0 \mathrm{~s}$ of welding for all 10 different LFW setups. In Fig. 19, in order to improve the visibility of respective curves, the profiles along path $\mathrm{I}-\mathrm{J}-\mathrm{K}-\mathrm{L}$ are presented by using continuous lines without identifying the points I, J, K and L.

Figure 19a shows that $\delta$ phase did not dissolve during LFW process of setup $\mathrm{J} 1$, because the temperature of weld is well below the $\delta$ phase equilibrium solvus temperature $\left(1010^{\circ} \mathrm{C}\right)$. For LFW setups $\mathrm{J} 2$ and $\mathrm{J} 3, \delta$ phase is fully dissolved at the friction interface between its centre and $x=5 \mathrm{~mm}$ and $x=6$ $\mathrm{mm}$, respectively, along the path $\mathrm{I}-\mathrm{J}-\mathrm{K}-\mathrm{L}$. In these regions of path $\mathrm{I}-\mathrm{J}-\mathrm{K}-\mathrm{L}$ where $\delta$ phase has been fully dissolved, the temperature is higher than the $\delta$ phase equilibrium solvus temperature. The maximum temperature of setup J3 (1460 $\left.{ }^{\circ} \mathrm{C}\right)$ is higher than that of $\mathrm{J} 2\left(1440{ }^{\circ} \mathrm{C}\right)$.

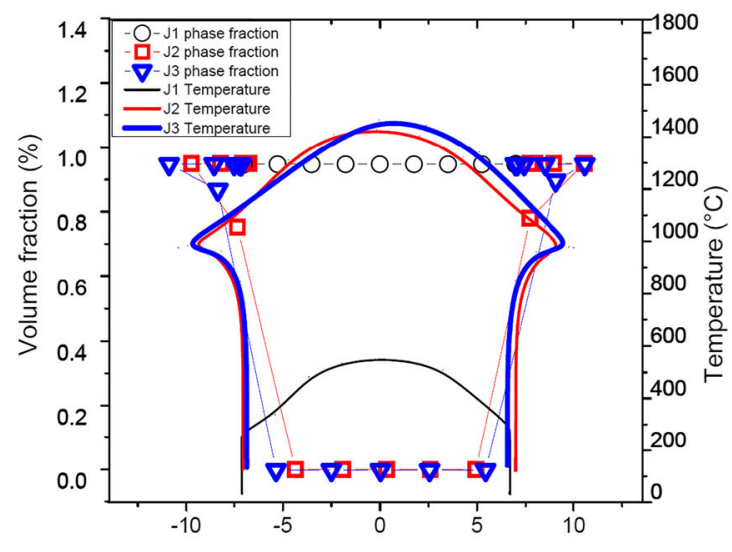

$\mathrm{X}$-axis coordinate value of points along path $\mathrm{I}-\mathrm{J}-\mathrm{K}-\mathrm{L}(\mathrm{mm})$

(a)

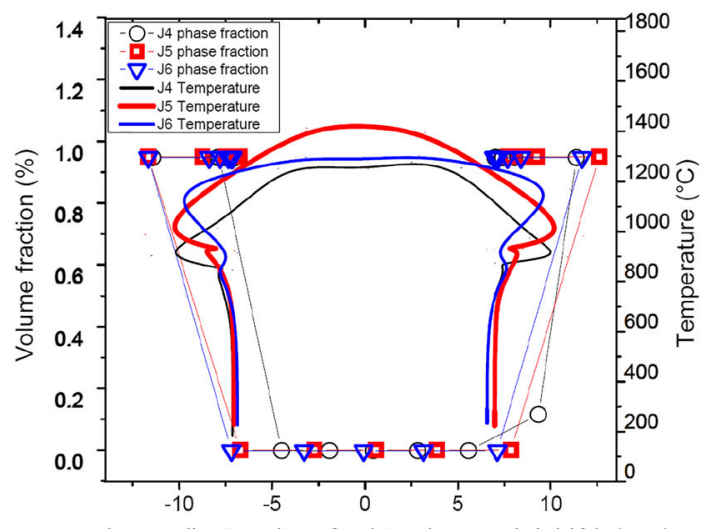

$\mathrm{X}$-axis coordinate value of points along path $\mathrm{I}-\mathrm{J}-\mathrm{K}-\mathrm{L}(\mathrm{mm})$

(b)
LFW setup J5 shows (in Fig. 19b) considerably higher temperature (maximum temperature of $1430.54{ }^{\circ} \mathrm{C}$ ) than the liquidus temperature of IN718 because of the higher level of oscillating amplitude employed. Similar results were found in the research [29]. For high friction pressure welding of IN718 (300 to $500 \mathrm{MPa}$ ), increasing the oscillating amplitude above $2.9 \mathrm{~mm}$ can result in extremely high weld temperature and excessive flash formation, because the rubbing velocity increases even at the same level of oscillating frequency of $25 \mathrm{~Hz}[22,23,30,47]$. The maximum temperature of LFW setups J4 $\left(1292.88^{\circ} \mathrm{C}\right)$ and $\mathrm{J} 6\left(1297.10^{\circ} \mathrm{C}\right)$ is slightly above the solidus temperature $\left(1250^{\circ} \mathrm{C}\right)$ of IN718 alloy. For LFW setup J4, J5 and J6, $\delta$ phase is fully dissolved at the friction interface up to $5 \mathrm{~mm}, 6 \mathrm{~mm}$ and $7 \mathrm{~mm}$, respectively, relative to its centre.

In Fig. 19c, $\delta$ phase did not dissolve for LFW setup J9 because the maximum temperature for $\mathrm{J} 9\left(658.54{ }^{\circ} \mathrm{C}\right)$ is below the $\delta$ phase equilibrium solvus temperature. For LFW setup J7, J8 and J10 shown in Fig. $19 \mathrm{c}$ and d, the $\delta$ phase is fully dissolved at the friction interface up to $3 \mathrm{~mm}, 6 \mathrm{~mm}$ and $4 \mathrm{~mm}$, respectively, relative to its centre.

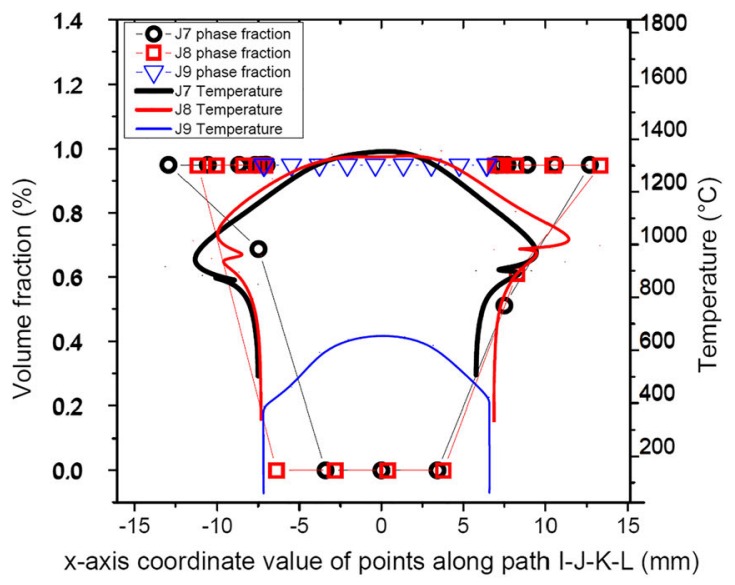

(c)

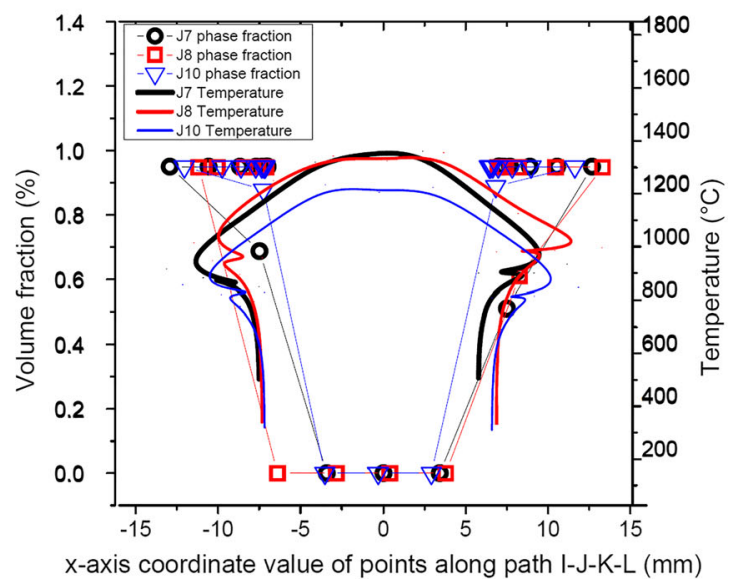

(d)

Fig. 19 Computational modelling results of profile of temperature and $\delta$ phase volume fraction along the path I-J-K-L for LFW setups a J1, J2 and J3; b $\mathrm{J} 4$, J5 and $\mathrm{J} 6$; $\mathbf{c} \mathrm{J} 7, \mathrm{~J} 8$ and $\mathrm{J} 9$; and $\mathbf{d} \mathrm{J} 7$, J8 and $\mathrm{J} 10$ 
The results shown in Fig. 19 a to d indicate that for different LFW setups, $\delta$ phase did not dissolve at the periphery of the bottom workpiece (such as approximately along paths I-J and $\mathrm{K}-\mathrm{L}$ ) because the temperature was relatively low. Temperature levels higher than the $\delta$ phase equilibrium solvus temperature were often observed near the centre of path $\mathrm{J}-\mathrm{K}$ (on the friction interface). Figure 19 a to $d$ show that, depending on the LFW process parameters, the path $\mathrm{I}-\mathrm{J}-\mathrm{K}-\mathrm{L}$ can be elongated from an initial length of $34.0 \mathrm{~mm}$ up to the maximum length of $79.4 \mathrm{~mm}$ (like the LFW setup J7). The path is significantly elongated for friction amplitude $A_{0}>2.9 \mathrm{~mm}$, friction frequency $f_{0}>25 \mathrm{~Hz}$ and specifically for higher friction pressure of $p_{f}>300 \mathrm{MPa}$ (like the LFW setups J3, J5, J7 and J8). More importantly, the region of fully dissolved $\delta$ phase gets wider when applying higher levels of friction pressure, increasing from 200 to $500 \mathrm{MPa}$ (like the LFW setups J2, $\mathrm{J} 4, \mathrm{~J} 6, \mathrm{~J} 8$ and J10). At the same level of friction pressure, for example, $400 \mathrm{MPa}$ (like in LFW setups J6, J7 and J8), the region of fully dissolved $\delta$ phase is increased when higher values of oscillating frequency $\left(f_{0}>25 \mathrm{~Hz}\right)$ and oscillating amplitude $\left(A_{0}>2.9 \mathrm{~mm}\right)$ are employed.

Modelling results of setups J1 and J9 show that no $\delta$ phase dissolution took place during LFW. The reason is that the level of maximum temperature is $606.2^{\circ} \mathrm{C}$ and $658.5^{\circ} \mathrm{C}$ for setups $\mathrm{J} 1$ and $\mathrm{J} 9$, which is below the equilibrium solvus temperature of $\delta$ phase. Setups J1 and J9 have very low level of oscillating amplitude and oscillating frequency, which are $1.5 \mathrm{~mm}$ and $25 \mathrm{~Hz}$, which result in too low level of energy input during LFW process. Other than setups $\mathrm{J} 1$ and $\mathrm{J}$ 9, there is $\delta$ phase dissolution happening to some extents in all other LFW configurations along the path $\mathrm{I}-\mathrm{J}-\mathrm{K}-\mathrm{L}$ (particularly at the friction interface) of weld. Partially dissolved phases can be observed between the temperature of $1015^{\circ} \mathrm{C}$ and $1220^{\circ} \mathrm{C}$. No $\delta$ phase dissolution can be seen below the temperature of $1015{ }^{\circ} \mathrm{C}$.

Along the path $\mathrm{J}-\mathrm{K}$, the average friction interface temperature and average $\delta$ phase volume fraction were analysed at $5.0 \mathrm{~s}$ of welding, and the results of analysis for all 10 different LFW setups can be found in Fig. 20. These average values were calculated by considering the temperature and $\delta$ phase volume fraction of all sampling points on path $\mathrm{J}-\mathrm{K}$ (friction interface) of the bottom workpiece at $5.0 \mathrm{~s}$ of welding. Overall, for all 10 different LFW configurations, the average $\delta$ phase fraction is low when the average friction interface temperature is high. The highest and lowest average friction interface temperature were calculated as $1240.62{ }^{\circ} \mathrm{C}$ and $490.59^{\circ} \mathrm{C}$ for setups $\mathrm{J} 4$ and $\mathrm{J} 1$, respectively. For all 10 different LFW setups, the values of average friction interface temperature are under $91 \%$ of the IN718 liquidus temperature, implying that no significant remelting occurred during LFW.

From the computational modelling results shown in Figs. 18, 19 and 20, it can be concluded that higher levels of friction pressure $(\geq 200 \mathrm{MPa})$, oscillating frequency $(\geq 25 \mathrm{~Hz})$ and

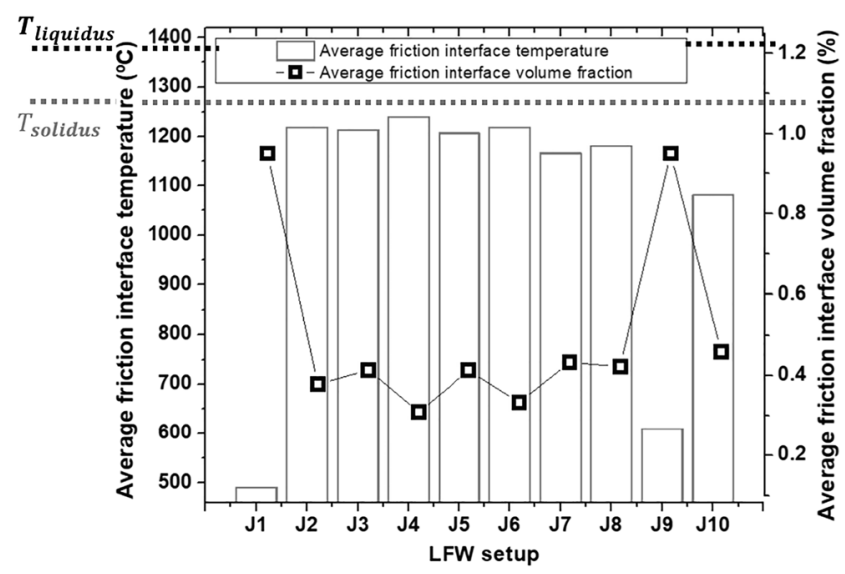

Fig. 20 Computational modelling results of friction interface average temperature and average $\delta$ phase volume fraction at $5.0 \mathrm{~s}$ of welding for 10 different LFW setups

oscillating amplitude $(\geq 2.9 \mathrm{~mm})$ result in higher energy input $\left(\geq 2307.7 \mathrm{~kW} \cdot \mathrm{m}^{-2}\right)$, higher average friction interface temperature $\left(\geq 1081.1^{\circ} \mathrm{C}\right)$ and corresponding lower average $\delta$ phase volume fraction at the friction interface $(\leq 0.46 \%)$. Compared to oscillating frequency and oscillating amplitude, friction pressure has the most significant influence on maximum and average friction interface temperature and average $\delta$ phase volume fraction at the friction interface (like LFW setups J2, $\mathrm{J} 4, \mathrm{~J} 6$, J8 and J10).

The integrated multiphysics computational modelling results have shown that amongst the LFW process parameters, friction pressure has the most significant influence on weld temperature and $\delta$ phase volume fraction, for example, at the friction interface of the weld. It was found by other researchers that the friction pressure dominates the weld zone characterised by significant $\delta$ phase dissolution and determines the size of the heat-affected zone (HAZ) $[10,12,16$, $42,45]$. In the study by Yang, the $\delta$ phase dissolution was noted to be more sensitive to the friction pressure and oscillating frequency than the oscillating amplitude [10]. In this study, $\delta$ phase at the friction interface can get completely dissolved during LFW process if its temperature can get sufficiently high.

\section{Summary and conclusions}

An integrated multiphysics computational modelling for LFW process was developed by sequentially coupling a thermomechanical model with microstructural model. This integrated multiphysics computational modelling considers mechanisms such as heat transfer, material elastic/plastic deformation and phase transformation. It is capable of computationally predicting the LFW process with regard to thermal history, stress/strain and $\delta$ phase evolution at the scale of the overall weld. It is the very first time ever that such an 
integrated multiphysics computational modelling has been developed for LFW process of IN718.

Computational modelling was used to predict the influence of process parameters (such as pressure, frequency and amplitude) on temperature, strain and $\delta$ phase fraction of IN718 LFW welds by running computations corresponding to 10 different LFW setups. It was found that pressure has the most significant influence, while frequency and amplitude have less significant influence. High pressure results in high temperature and complete dissolution of $\delta$ phase at the friction interface of weld. Thus, this study demonstrates how the integrated multiphysics computational modelling can be used to systematically analyse the processes and optimise the process parameters for IN718 LFW. Besides completing related model verification, the modelling results were used to interpret related experimental results of other researchers in relation to why high material hardness and small grain size are commonly found at the friction interface of weld. Such modelling tools can enable the manufacturing industry to improve the design of LFW process parameters in a timely and cost-effective manner.

Acknowledgements The authors gratefully acknowledge the enabling computational modelling platform provided by the Irish Centre for High-End Computing (ICHEC), Ireland.

Author contribution Saviour I. Okeke: conceptualization, data curation, formal analysis, investigation, methodology, software, verification, visualisation and writing - original draft.

Harrison M. Noel: funding acquisition, supervision, conceptualization and writing - review and editing.

Mingming Tong: funding acquisition, supervision, conceptualization, project management and writing - review and editing.

Funding Open Access funding provided by the IReL Consortium. This study was supported by the School of Engineering, College of Science and Engineering Postgraduate Scholarship, National University of Ireland Galway. This publication has emanated from research supported in part by a grant from the Science Foundation Ireland under Grant number 16/ RC/3872. For the purpose of Open Access, the author has applied a CC BY public copyright licence to any Author Accepted Manuscript version arising from this submission.

Availability of data and material The data used to support the findings of this study are available from the funding source on demand.

\section{Declarations}

Ethical approval Not applicable.

Consent to participate Not applicable.

Consent to publish Not applicable.

Conflict of interest The authors declare no competing interests.
Open Access This article is licensed under a Creative Commons Attribution 4.0 International License, which permits use, sharing, adaptation, distribution and reproduction in any medium or format, as long as you give appropriate credit to the original author(s) and the source, provide a link to the Creative Commons licence, and indicate if changes were made. The images or other third party material in this article are included in the article's Creative Commons licence, unless indicated otherwise in a credit line to the material. If material is not included in the article's Creative Commons licence and your intended use is not permitted by statutory regulation or exceeds the permitted use, you will need to obtain permission directly from the copyright holder. To view a copy of this licence, visit http://creativecommons.org/licenses/by/4.0/.

\section{References}

1. Chamanfar A, Jahazi M, Cormier J (2015) A review on inertia and linear friction welding of Ni-based superalloys. Metall Mater Trans $\mathrm{A} \backslash$ (4):1639-1669. https://doi.org/10.1007/s11661-015-2752-4

2. McAndrew AR, Colegrove PA, Buhr C, Flipo BCD, Vairis A (2018) A literature review of Ti-6Al-4V linear friction welding. Prog Mater Sci 92:225-257. https://doi.org/10.1016/j.pmatsci. 2017.10.003

3. Mateo-Garcia AM (2011) BLISK fabrication by linear friction welding. Advances in Gas Turbine Technology:411-434. https:// doi.org/10.5772/21278

4. Vishwakarma KR, Ojo OA, Wanjara P, Chaturvedi MC (2014) Microstructural analysis of linear friction-welded 718 plus superalloy. JOM 66(12):2525-2534. https://doi.org/10.1007/s11837-0140938-7

5. Reed RC (2006) The superalloys: fundamentals and applications. Cambridge University Press, Cambridge, England

6. Vishwakarma KR, Ojo OA, Wanjara P, Chaturvedi MC (2010) Linear friction welding of Allvac ${ }^{\circledR} 718$ plus superalloy. 7th International Symposium on Superalloy 718 and Derivatives, TMS https://doi.org/10.7449/2010/Superalloys_2010_413_426

7. Azadian S, Wei LY, Warren R (2004) Delta phase precipitation in Inconel 718. Mater Charact 53(1):7-16. https://doi.org/10.1016/j. matchar.2004.07.004

8. Beaubois V, Huez J, Coste S, Brucelle O, Lacaze J (2004) Short term precipitation kinetics of delta phase in strain free Inconel 718 alloy. Mater Sci Technol 20(8):1019-1026. https://doi.org/10. 1179/026708304225019830

9. Radavich JF (1989) The physical metallurgy of cast and wrought alloy 718. Superalloy 718 - Metallurgy and Applications: 229-240. https://doi.org/10.7449/1989/Superalloys_1989_229_240

10. Yang J (2014) Microstructure-property development in linear friction welding of nickel-based superalloys. PhD thesis, The University of Birmingham

11. Geng P, Qin G, Li T, Zhou J, Zou Z, Yang F (2019) Microstructural characterization and mechanical property of GH4169 superalloy joints obtained by linear friction welding. J Manuf Process 45: 100-114. https://doi.org/10.1016/j.jmapro.2019.06.032

12. Smith M, Bichler L, Gholipour J, Wanjara P (2016) Mechanical properties and microstructural evolution of in-service Inconel 718 superalloy repaired by linear friction welding. Int J Adv Manuf Technol 90(5-8):1931-1946. https://doi.org/10.1007/s00170-0169515-2

13. Ma TJ, Chen X, Li WY, Yang XW, Zhang Y, Yang SQ (2016) Microstructure and mechanical property of linear friction welded nickel-based superalloy joint. Mater Design 89:85-93. https://doi. org/10.1016/j.matdes.2015.09.143

14. Mehl ME (1997) Effect of $\delta$-phase precipitation on the repair weldability of alloy 718 . Superalloys $718,625,706$ and Various 
Derivatives. Metals and Materials Society, TMS:731-741. https:// doi.org/10.7449/2005/Superalloys_2005_351_362

15. Burke MG, Miller MK (1991) Precipitation in alloy 718: a combined AEM and APFIM investigation. Superalloys 718, 625, and Various Derivatives. The Minerals, Metals \& Materials Society (TMS):337-350. https://doi.org/10.7449/1991/Superalloys_1991 337_350

16. Mary C, Jahazi M (2008) Multi-scale analysis of IN-718 microstructure evolution during linear friction welding. Adv Eng Mater 10:573-578. https://doi.org/10.1002/adem.200700361

17. Roder O, Helm D, Neft S, Albrecht J, Luetjering G (2005) Mixed Inconel Alloy 718 inertia welds for rotating applications: microstructures and mechanical properties. 6th International Conference on Superalloys 718, 625, 706, and Derivatives. The Minerals, Metals \& Materials Society (TMS):649-658. https://doi.org/10. 7449/2005/Superalloys_2005_649_658

18. Preuss M, Withers PJ, Baxter GJ (2006) A comparison of inertia friction welds in three nickel base superalloys. Mater Sci Eng A 437(1):38-45. https://doi.org/10.1016/j.msea.2006.04.058

19. Soucail M, Bienvenu Y (1996) Dissolution of the $\gamma^{\prime}$ phase in a nickel base superalloy at equilibrium and under rapid heating. Mat Sci Eng a-Struct 220(1-2):215-222. https://doi.org/10.1016/ S0921-5093(97)80011-1

20. Masoumi F, Jahazi M, Cormier J, Shahriari D (2014) Dissolution kinetics and morphological changes of $\gamma^{\prime}$ in $\mathrm{AD} 730^{\mathrm{TM}}$ superalloy. Eurosuperalloys 14. https://doi.org/10.1051/matecconf/ 20141413005

21. Masoumi F, Jahazi M, Shahriari D, Cormier J (2016) Coarsening and dissolution of $\gamma^{\prime}$ precipitates during solution treatment of AD730 ${ }^{\mathrm{TM}}$ Ni-based superalloy: mechanisms and kinetics models. J Alloys Compd 658:981-995. https://doi.org/10.1016/j.jallcom. 2015.11.002

22. Geng PH, Qin GL, Chen L, Zhou J, Zou ZD (2019) Simulation of plastic flow driven by periodically alternating pressure and related deformation mechanism in linear friction welding Mater Design: 178. https://doi.org/10.1016/j.matdes.2019.107863

23. Qin GL, Geng PH, Zhou J, Zou ZD (2019) Modeling of thermomechanical coupling in linear friction welding of Ni-based superalloy. Mater Design 172:1-18. https://doi.org/10.1016/j.matdes. 2019.107766

24. Masoumi F, Shahriari D, Monajati H, Cormier J, Flipo BCD, Devaux A, Jahazi M (2019) Linear friction welding of AD730 ${ }^{\mathrm{TM}}$ Ni-base superalloy: process-microstructure-property interactions. Mater Design 183:108117. https://doi.org/10.1016/j.matdes.2019. 108117

25. Wang FF, Li WY, Li JL, Vairis A (2014) Process parameter analysis of inertia friction welding nickel-based superalloy. Int J Adv Manuf Technol 71(9-12):1909-1918. https://doi.org/10.1007/ s00170-013-5569-6

26. Wang X, Li W, Ma T, Yang X, Vairis A (2019) Effect of welding parameters on the microstructure and mechanical properties of linear friction welded Ti-6.5Al-3.5Mo-1.5Zr-0.3Si joints. J Manuf Process 46:100-108. https://doi.org/10.1016/j.jmapro.2019.08.031

27. Payton EJ, Wynn TA, Mills MJ (2012) Experimental measurement of the kinetics of gamma prime dissolution during supersolvus heat treatment of powder metallurgical Ni-based disk superalloys. J Mater Sci 47(20):7305-7311. https://doi.org/10.1007/s10853-0126684-8

28. Semiatin SL, Levkulich NC, Saurber AE, Mahaffey DW, Payton EJ, Senkov ON (2017) The kinetics of precipitate dissolution in a nickel-base superalloy. Metall Mater Trans A 48(11):5567-5578. https://doi.org/10.1007/s11661-017-4322-4

29. Okeke SI, Harrison N, Tong M (2020) Thermomechanical modelling for the linear friction welding process of Ni-based superalloy and verification. Proc IMechE Part L: J Materials: Design and
Applications 234(5):1-20. https://doi.org/10.1177/ 1464420719900780journals.sagepub.com/home/pil

30. Geng P, Qin G, Zhou J (2020) A computational modeling of fully friction contact-interaction in linear friction welding of Ni-based superalloys. Mater Design:185. https://doi.org/10.1016/j.matdes. 2019.108244

31. Geng PH, Qin GL, Zhou J, Zou ZD (2019) Finite element models of friction behaviour in linear friction welding of a Ni-based superalloy. Int J Mech Sci 152:420-431. https://doi.org/10.1016/j. ijmecsci.2019.01.014

32. Yang XW, Li WY, Li JL, Xiao B, Ma TJ, Huang Z, Guo J (2015) Finite element modeling of the linear friction welding of GH4169 superalloy. Mater Design 87:215-230. https://doi.org/10.1016/j. matdes.2015.08.036

33. Geng P, Qin G, Li T, Zhou J, Zou Z (2018) Hot deformation behavior and constitutive model of GH4169 superalloy for linear friction welding process. J Manuf Process 32:469-481. https://doi.org/ 10.1016/j.jmapro.2018.03.017

34. Geng P, Qin G, Li C, Wang H, Zhou J (2020) Study on the importance of thermo-elastic effects in FE simulations of linear friction welding. J Manuf Process 56:602-615. https://doi.org/10.1016/j. jmapro.2020.05.051

35. Geng P, Qin G, Ma H, Zhou J, Ma N (2021) Linear friction welding of dissimilar Ni-based superalloys: microstructure evolution and thermo-mechanical interaction. J Mater Res Technol 11:633-649. https://doi.org/10.1016/j.jmrt.2021.01.036

36. Dassault-Systèmes (2017) Abaqus 2017 analysis user's guide Volume II: analysis. https://www.3ds.com/products-services/ simulia/services-support/support/documentation/ Accessed 14th May 2020

37. Grujicic M, Yavari R, Snipes JS, Ramaswami S (2014) A linear friction welding process model for Carpenter Custom 465 precipitation-hardened martensitic stainless steel: a weld microstructure-evolution analysis. Proc Inst Mech Eng B J Eng Manuf 229(11):1997-2020. https://doi.org/10.1177/ 0954405414542137

38. Schmidt H, Hattel J (2005) A local model for the thermomechanical conditions in friction stir welding. Model Simul Mater Sci Eng 13(1):77-93. https://doi.org/10.1088/0965-0393/13/1/006

39. Grujicic M, Yavari R, Snipes JS, Ramaswami S, Yen CF, Cheeseman BA (2014) Linear friction welding process model for Carpenter Custom 465 precipitation-hardened martensitic stainless steel. J Mater Eng Perform 23(6):2182-2198. https://doi.org/10. 1007/s11665-014-0985-9

40. Soucail M, Moal A, Naze L, Massoni E, Levaillant C, Bienvenu Y (1992) Microstructural study and numerical-simulation of inertia friction welding of astroloy. Superalloys:847-856. https://doi.org/ 10.7449/1992/Superalloys_1992_847_856

41. Devaux A, Naze L, Molins R, Pineau A, Organista A, Guedou JY, Uginet JF, Heritier P (2008) Gamma double prime precipitation kinetic in Alloy 718. Mat Sci Eng a-Struct 486(1-2):117-122. https://doi.org/10.1016/j.msea.2007.08.046

42. Chamanfar A, Jahazi M, Gholipour J, Wanjara P, Yue S (2011) Mechanical property and microstructure of linear friction welded Waspaloy. Metall Mater Trans A 42a(3):729-744. https://doi.org/ 10.1007/s11661-010-0457-2

43. Vairis A, Frost M (1998) High frequency linear friction welding of a titanium alloy. Wear 217(1):117-131. https://doi.org/10.1016/ s0043-1648(98)00145-8

44. Vairis A, Frost M (2000) Modelling the linear friction welding of titanium blocks. Mater Sci Eng A 292(1):8-17. https://doi.org/10. 1016/s0921-5093(00)01036-4

45. Chamanfar A, Jahazi M, Gholipour J, Wanjara P, Yue S (2012) Maximizing the integrity of linear friction welded Waspaloy. Mater Sci Eng A 555:117-130. https://doi.org/10.1016/j.msea. 2012.06.041 
46. Mary C, Jahazi M (2007) Linear friction welding of IN-718 process optimization and microstructure evolution. 5th International Conference on Processing and Manufacturing of Advanced Materials. Coll Advanced Materials Research: Trans Tech Publications 15-17:357-362. https://doi.org/10.4028/www. scientific.net/AMR.15-17.357

47. Ofem UU, Colegrove PA, Addison A, Russell MJ (2013) Energy and force analysis of linear friction welds in medium carbon steel.
Sci Technol Weld Join 15(6):479-485. https://doi.org/10.1179/ $136217110 X 12731414739790$

Publisher's note Springer Nature remains neutral with regard to jurisdictional claims in published maps and institutional affiliations. 